\title{
Investigation of superstorm Sandy 2012 in a multi-disciplinary approach
}

\author{
M. Kunz ${ }^{1,2}$, B. Mühr ${ }^{1,2}$, T. Kunz-Plapp ${ }^{1,3}$, J. E. Daniell ${ }^{1,3}$, B. Khazai ${ }^{1,3}$, F. Wenzel ${ }^{1,3}$, M. Vannieuwenhuyse ${ }^{1,4}$, \\ T. Comes ${ }^{1,4}$, F. Elmer ${ }^{1,5}$, K. Schröter ${ }^{1,6}$, J. Fohringer ${ }^{1,7}$, T. Münzberg ${ }^{1,8}$, C. Lucas ${ }^{1,9}$, and J. Zschau ${ }^{1,10}$ \\ ${ }^{1}$ Center for Disaster Management and Risk Reduction Technology (CEDIM), Potsdam and Karlsruhe, Germany \\ ${ }^{2}$ Institute for Meteorology and Climate Research (IMK-TRO), Karlsruhe Institute of Technology (KIT), Karlsruhe, Germany \\ ${ }^{3}$ Geophysical Institute (GPI), Karlsruhe Institute of Technology (KIT), Karlsruhe, Germany \\ ${ }^{4}$ Institute for Industrial Production (IIP), Karlsruhe Institute of Technology (KIT), Karlsruhe, Germany \\ ${ }^{5}$ Scientific Infrastructure and Platforms, GFZ German Research Centre for Geosciences, Potsdam, Germany \\ ${ }^{6}$ Section Hydrology, GFZ German Research Centre for Geosciences, Potsdam, Germany \\ ${ }^{7}$ Section Geoinformatics, GFZ German Research Centre for Geosciences, Potsdam, Germany \\ ${ }^{8}$ Institute for Nuclear and Energy Technologies (IKET), Karlsruhe Institute of Technology (KIT), Karlsruhe, Germany \\ ${ }^{9}$ Institute of Photogrammetry and Remote Sensing (IPF), Karlsruhe Institute of Technology (KIT), Karlsruhe, Germany \\ ${ }^{10}$ Section Earthquake Risk and Early Warning, GFZ German Research Centre for Geosciences, Potsdam, Germany
}

Correspondence to: M. Kunz (michael.kunz@kit.edu)

Received: 8 January 2013 - Published in Nat. Hazards Earth Syst. Sci. Discuss.: 25 March 2013

Revised: 3 July 2013 - Accepted: 6 September 2013 - Published: 18 October 2013

\begin{abstract}
At the end of October 2012, Hurricane Sandy moved from the Caribbean Sea into the Atlantic Ocean and entered the United States not far from New York. Along its track, Sandy caused more than 200 fatalities and severe losses in Jamaica, The Bahamas, Haiti, Cuba, and the US. This paper demonstrates the capability and potential for nearreal-time analysis of catastrophes.

It is shown that the impact of Sandy was driven by the superposition of different extremes (high wind speeds, storm surge, heavy precipitation) and by cascading effects. In particular the interaction between Sandy and an extra-tropical weather system created a huge storm that affected large areas in the US. It is examined how Sandy compares to historic hurricane events, both from a hydro-meteorological and impact perspective.

The distribution of losses to different sectors of the economy is calculated with simple input-output models as well as government estimates. Direct economic losses are estimated about USD 4.2 billion in the Caribbean and between USD 78 and 97 billion in the US. Indirect economic losses from power outages is estimated in the order of USD 16.3 billion. Modelling sector-specific dependencies quantifies total business interruption losses between USD 10.8 and 15.5 billion.
\end{abstract}

Thus, seven years after the record impact of Hurricane Katrina in 2005, Hurricane Sandy is the second costliest hurricane in the history of the United States.

\section{Introduction}

Hurricane Sandy was the last tropical cyclone (TC) of the 2012 Northern Atlantic Hurricane season. From 24 to 30 October, Sandy moved on an unusual track from the Caribbean to the East Coast of the United States, where it made landfall in New Jersey in the early hours of 30 October. Along its path, the severe storm caused more than 200 fatalities and widespread damage to one the poorest (Haiti) and one of the richest countries (US) in the world with different patterns of impact and loss. Sandy was an extraordinary event due to its multihazard nature and the cascades of adverse events in the aftermath that aggravated the direct impacts significantly.

From a hydro-meteorological perspective, the most unusual aspect was the very large spatial extent of up to $1700 \mathrm{~km}$, primarily a result of the interaction of the TC with an upper-tropospheric trough. This interaction led to a rapid extra-tropical transition (e.g., Jones et al., 2003) 
shortly before landfall that further increased the strength of the storm. High wind speeds were associated with recordbreaking storm surges on the US. Mid-Atlantic and New England Coast during high (astronomical) tide, leading to widespread flooding. Very unusual was also the storm's track from the south to the north, which was mainly due to blocking by an extended high pressure system. Thus, Sandy hit a region that has rarely been affected by hurricanes in the past but is densely populated and very vulnerable to such an unexpected event. Since recording, Sandy was only the third hurricane that made landfall in New Jersey.

Though Sandy was not the most severe storm event in terms of wind speed and precipitation, the impact, particularly in the US, was enormous. More than 20 million people on the East Coast were affected by power outages that lasted a few days to weeks in some regions. Furthermore, many places on the East Coast suffered several days from shortages in fuel supply. This situation was aggravated by a cold air outbreak in the days following the event, causing temperatures to drop down to almost $0{ }^{\circ} \mathrm{C}$. Total damage will be in excess of USD 100 billion, with our estimates ranging between USD 78 and 97 billion for direct damage and over USD 10 to 16 billion for indirect damage due to business interruption. Seven years after the record impact of Hurricane Katrina in 2005 (e.g., Daniels et al., 2006) with total economic losses in the order of USD 160 (inflation-adjusted to 2012; Swiss Re, 2006), Sandy was the second most costliest TC in the history of the United States.

The new Forensic Disaster Analysis (FDA) Task Force of the Center for Disaster Management and Risk Reduction Technology (CEDIM) intends to improve our understanding of the temporal evolution and the impact of natural disasters. The main research strategy is to consider not only the natural hazard components, but also the related complex interactions and cascading effects in and between the natural, social, economic and infrastructure system. This is implemented in an interdisciplinary way by collecting and compiling scattered and distributed information from available databases and sources via the Internet, by application of our own methodologies and models for near-real-time analyses developed in recent years, and by expert knowledge. Although much better data emerge weeks and months after such an event, the CEDIM FDA concept attempts to obtain and provide information within the first few hours to days after a disaster. Time critically is considered important as potential user interest (e.g., relief organizations, insurance industry, tourist agencies) peaks in the initial stage of a disaster. Also, many pieces of information emerge within the first days that may later be obscured by a flood of information. Initial hypotheses on loss evolution and its implications can be tested in the following days and, thus, may enhance our understanding of the impact and evolution of natural disasters within their respective socio-economic context.

This paper draws on two reports that are available on CEDIM's webpage (www.cedim.de), the first one of
30 October 2012, $20 \mathrm{~h}$ after Sandy had crossed the US East Coast, and the second one 10 days later. The paper describes the multihazard situation that led to the extraordinary event, highlights the interaction of the TC with other hydrometeorological events, and examines impacts such as social and economic losses including cascading effects, for example, due to power outages. It is examined how Sandy compares to historic hurricane events in the US, both from the hydro-meteorological and impact perspective. Direct and indirect losses are estimated by comparison with past events and by application of an economic loss model that describes the dependencies between the various economic sectors.

The paper is structured as follows. Section 2 describes background, procedure, and strategy of CEDIM's near-realtime FDA. Section 3 gives an overview of the hazard situation and discusses what made Sandy an extraordinary event. While Sect. 4 examines the impact of Sandy during the early stages in the Caribbean, Sect. 5 discusses the impact specifically for the US, with a focus on power outages, their consequences and associated indirect losses. Finally, Sect. 6 briefly summarizes the various findings, lists some conclusions, and discusses future perspectives and requirements that are necessary for implementing near-real-time FDA.

\section{CEDIM forensic disaster analysis}

Modern technologies, accessible databases and information services open unprecedented opportunities for natural disaster loss assessment and analysis in near-real time. The Internet, for instance, provides information from various sources, including the new technique of crowd sourcing, in minutes to hours after an extreme event anywhere on the globe. Databases have been developed for storms, floods, or earthquakes, which allow the rapid estimation of the potential damage once the triggering parameters, such as gust wind speed, precipitation totals, or ground motion are roughly known. Moreover, several services are accessible with highly relevant disaster information; among these are the Joint Research Center (JRC) with its GDACS service (www.gdacs. org), as well as the CatWatch (www.eqecat.com) information service from the private sector.

Forensic disaster investigation (Burton, 2011) has been implemented as a research target by the Integrated Research on Disaster Risk (IRDR, www.irdrinternational.org), an ICSU (International Council for Science, www.icsu.org) initiative located in Beijing. The Forensic Investigations of Disasters (FORIN) programme (IRDR, 2011) aims at uncovering the root causes of natural disasters through in-depth investigations that go beyond the typical sectoral case studies. For disaster analysis in near-real time, which is not the pretension in the FORIN concept, CEDIM is developing the strategy of Forensic Disaster Analysis (FDA; Wenzel et al., 2012). The word "forensic" is applied in the sense of scrutinising disasters closely and with a multi-disciplinary 
approach by making use of the high potential of modern observational and analytical methodologies available in science, engineering, remote sensing and information technology. Results from these heterogeneous sources are the starting point for comprehensive science-based assessments in near-real time, i.e. less than $24 \mathrm{~h}$ after a catastrophic event occurred. This information are complemented by our own models for near-real time-loss estimates that are currently being developed. The forensic approach incorporates eventtriggered task force activities, as well as specific research towards new methodologies that can support the near-real-time approach.

The objective of CEDIM's FDA approach are to build up the capability to rapidly:

- generate a portrait of the disaster with the aims of revealing its main characteristics and tracking its evolution;

- reveal the short- and long-term impacts on regional and national scale;

- estimate potential losses and analyze the critical causes of loss and risk;

- contribute to the development of a framework for future loss and risk reduction.

An important component in the CEDIM FDA is the nearreal-time approach as: (i) many pieces of information emerge within the first days of disasters; (ii) interest of and interaction with potential users (e.g., emergency services, tourism industry, insurance industry, relief agencies) is particular high during the initial stage of a disaster; (iii) methodologies and models of CEDIM for near-real-time loss evolution and implications can be tested and calibrated and can thus (iv) contribute to significantly speed up our understanding of disasters within their respective socio-economic contexts.

\section{Hazard description}

\subsection{Overview of Sandy}

From 22-29 October 2012, Hurricane Sandy made its way from the Caribbean Sea into the Atlantic Ocean and finally entered the United States near Atlantic City (NJ) on the early morning of 30 October. According to the Saffir-Simpson Hurricane Scale ranging from 1 to 5, Sandy was a category 2 Hurricane $\left(154-177 \mathrm{kmh}^{-1}\right)$. The very unusual coincidence of reinforcing conditions over the US, e.g. the interaction between Sandy and an extra-tropical weather system, created a huge storm that made landfall in the US and affected large areas. The storm was associated with high impact weather that stretched up to the Great Lakes and even beyond in southern and southeastern Canada. Due to the huge spatial extension and high intensity, Sandy caused massive damage and losses in several of the densely populated New England and MidAtlantic states.

A coastline of more than $1000 \mathrm{~km}$ in length was hit by a significant storm surge with the highest and often recordbreaking water levels occurring north of the landfall location in New Jersey and New York. In contrast, fluvial flooding in the Mid-Atlantic region in response to heavy precipitation turned out to be a minor hazardous effect.

In the next subsections, the storm track, the spatialtemporal evolution of Sandy and its hazardous effects, heavy precipitation, storm surge, and river floods are presented.

\subsection{Storm track of Sandy}

Sandy was added to the list of 2012 tropical storm systems on 22 October, 15:00 UTC. So far that year, it was tropical storm system \#18 in the North Atlantic region. At the initial stage, huge convective cloud structures begun to organize $250 \mathrm{~km}$ north of Panama and $515 \mathrm{~km}$ south of Kingston, Jamaica. With further strengthening, Sandy was classified as a category 1 hurricane according to the Saffir-Simpson Hurricane Scale on 24 October, just before crossing the island of Jamaica. Heading further north, the hurricane approached Cuba, where the storm center arrived $24 \mathrm{~h}$ later. Associated with heavy rainfall, Sandy crossed the eastern parts of Cuba, where it reached its maximum intensity. At 06:00 UTC on 25 October, the TC had $1 \mathrm{~min}$ sustained winds of $95 \mathrm{kts}$ $\left(176 \mathrm{~km} \mathrm{~h}^{-1}\right)$ and gusts around $110 \mathrm{kts}\left(204 \mathrm{kmh}^{-1}\right)$ making Sandy a category 2 hurricane.

Constant in intensity, Sandy passed The Bahamas on 26 October. The following day the hurricane made a right turn towards the northeast and started to lose strength. More and more weather forecast models began to predict a scenario where Sandy was expected to make landfall after a leftward movement on the East Coast of the US. The TC was expected to arrive in the night 29/30 October somewhere along the Delaware/New Jersey Atlantic coast.

Some hours before entering the US mainland, the hurricane intensified again and showed mean wind speeds of $80 \mathrm{kts}\left(148 \mathrm{~km} \mathrm{~h}^{-1}\right)$. Shortly before and while making landfall, the center pressure of Sandy was $940 \mathrm{hPa}$, which was a new low pressure record for hurricanes making landfall north of Cape Hatteras (Hurricane Gladys in 1977 showed a minimum pressure of $939 \mathrm{hPa}$, however, kept its center away from the coast). Even the well-known "Long Island Express" in 1938 only had a minimum pressure of $947 \mathrm{hPa}$. The storm center of Sandy crossed the coastline around 00:00 UTC on 30 October. From 30 to 31 October, Sandy moved further northwards and finally dissipated near Lake Erie. 
Table 1. Selected recordings of peak wind gusts and precipitation amounts during Sandy on 29 and 30 October 2012. Data source: NOAA Global Summary of the day and Ogimet.com.

\begin{tabular}{|c|c|c|c|c|}
\hline Station & \multicolumn{2}{|c|}{ peak wind gusts in $\mathrm{kmh}^{-1}$} & \multicolumn{2}{|c|}{ precipitation in $\mathrm{mm}$} \\
\hline Atlantic City Intl. Airport, NJ & 94.6 & 90.7 & 58.9 & 88.4 \\
\hline Baltimore/Washington Intl. Airport & 77.8 & 94.6 & 31.5 & 133.9 \\
\hline New York JFK Intl. Airport, NY & 127.8 & 109.5 & 0.5 & 13.0 \\
\hline New York La Guardia Intl. Airport, NY & 109.5 & 114.8 & 0.0 & 13.7 \\
\hline Philadelphia Intl. Airport, NJ & 85.2 & 87.0 & 24.4 & 55.9 \\
\hline Wallops Island, VA & 109.5 & 70.6 & 111.8 & 102.1 \\
\hline Patuxent River, MD & 90.7 & 77.8 & 84.8 & 123.2 \\
\hline Newark Intl. Airport, NJ & 125.9 & 120.6 & 1.5 & 25.7 \\
\hline Teterboro Airport, NJ & 116.5 & 105.4 & 0.0 & 18.8 \\
\hline
\end{tabular}

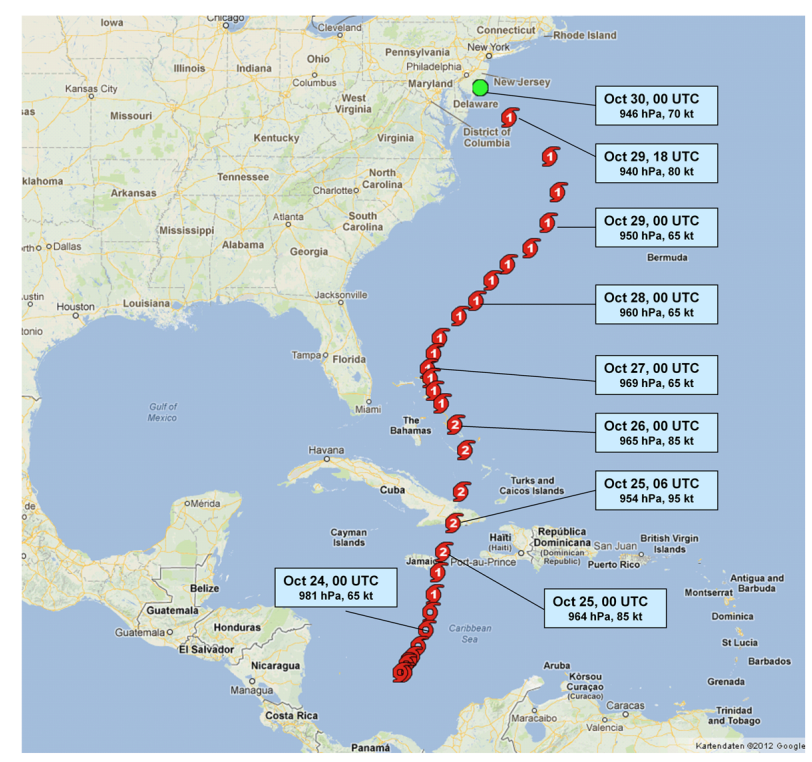

Fig. 1. Track of Hurricane Sandy from 24 to 30 October 2012. Indicated are storm category according to the Saffir-Simpson Hurricane Scale, minimum pressure and maximum 1 min sustained wind speed (in knots). Data source: National Hurricane Center.

\subsection{Space-time evolution of Sandy}

Wind speed and extreme precipitation are the primary hazards associated with hurricanes and also contributed significantly to the overall impact of Sandy. These primary hazards may trigger secondary hazards with even stronger impacts. Among the different types of secondary hazards, flooding is the most relevant one. Two different types of floods can be distinguished: storm surges that are caused by water masses driven onto the coastlines by strong winds, and fluvial floods that may result from heavy precipitation. An overview of the temporal evolution of winds, pressure, and water levels is given in Fig. 4 for two exemplary locations in New York and Washington DC region.

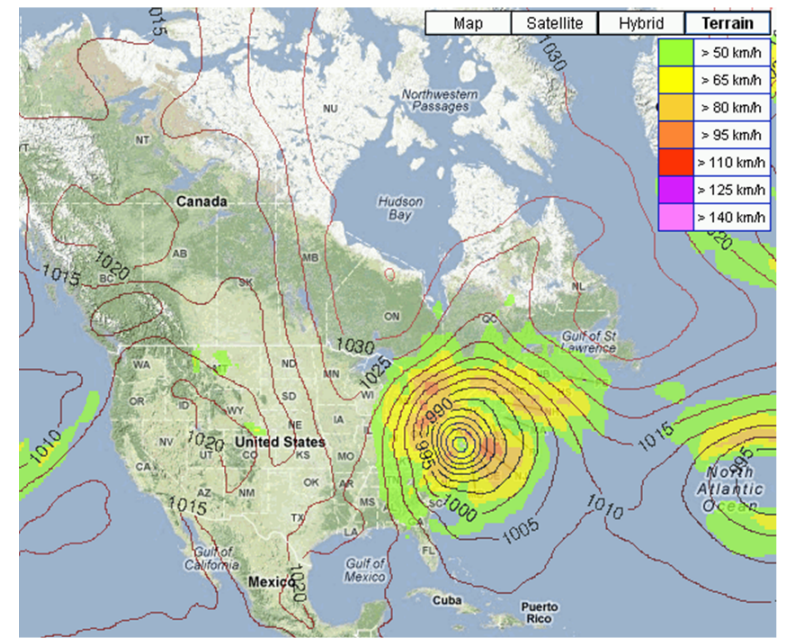

Fig. 2. Wind peak gusts on 30 October 2012 (GFS-model 6hforecast). Image credit: www.wettergefahren-fruehwarnung.de.

\subsubsection{Heavy precipitation and storm force winds}

While Sandy began to build, heavy precipitation with rainfall totals between 200 and $250 \mathrm{~mm}$ led to widespread flooding in the very south of the Dominican Republic as well as in the southwestern tip of Haiti. Over the eastern parts of Jamaica, more than $200 \mathrm{~mm}$ of rainfall was recorded, while the western parts did not receive significant rainfall. In Cuba, rainfall in excess of $200 \mathrm{~mm}$ were observed only in some easterly and central provinces. Furthermore, precipitation signals obtained from satellite sensors showed values around $250 \mathrm{~mm}$ in the vicinity of The Bahamas (Fig. 3, left). However, rainfall had its peak maximum over the open waters of the Caribbean Sea.

In the US, the states of Pennsylvania, Maryland, New Jersey, Delaware and Virginia were affected strongest by heavy rainfall between 100 and $200 \mathrm{~mm}$ (see Table 1 and Fig. 3, right). Wallops Island (Virginia) recorded a total of $214 \mathrm{~mm}$ 

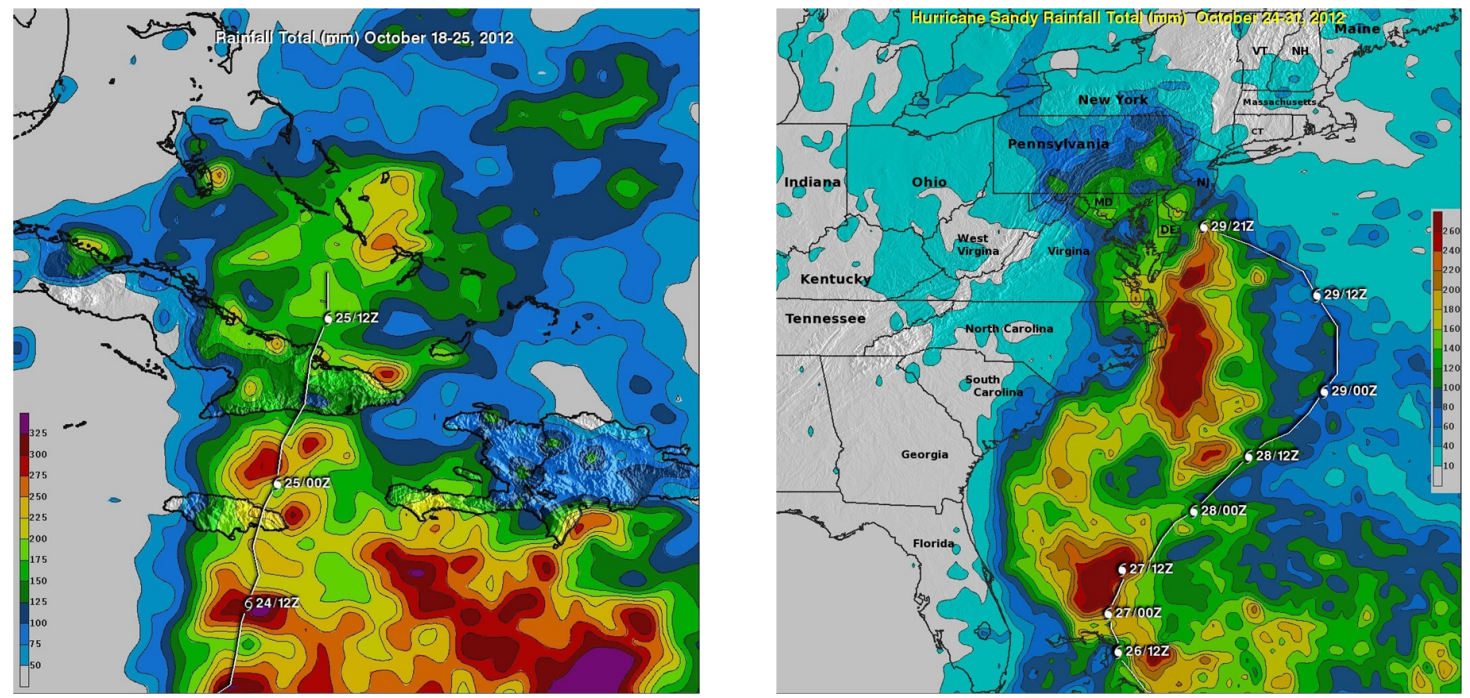

Fig. 3. Rainfall totals (in mm) from 18-25 October 2012 (left) over the Caribbean and 24-31 October (right) over the US East Coast. Image credit: TRMM Tropical Rainfall Measuring Mission.

within $48 \mathrm{~h}$, while at Baltimore/Washington Intl. Airport it was $165 \mathrm{~mm}$ (Fig. 4f). The most intense rainfall occurred in the vicinity of the Chesapeake Bay (Easton, MD, $319 \mathrm{~mm}$ ). Sandy was responsible for the wettest days that have ever been recorded in October at Baltimore/Washington Intl. Airport as well as at Dulles Intl. Airport.

The intrusion of cold air near the surface from the northwest led to heavy snowfall, especially in the southern and central Appalachian Mountains. In mountainous areas of Tennessee, Kentucky, North Carolina, West Virginia and Virginia people experienced blizzard-like conditions and snow amounts of up to $1 \mathrm{~m}$.

Many parts between the Atlantic coast and the Great Lakes experienced wind gusts in excess of $85 \mathrm{kmh}^{-1}$. Selected recordings of peak wind gusts on 29 and 30 October are shown in Table 1. The strongest winds occurred along and near the coastlines of Virginia, Delaware, New Jersey and parts of New York. At JFK Intl. airport in NYC, the highest gust recording was $128 \mathrm{~km} \mathrm{~h}^{-1}$ (see time series of Fig. $4 \mathrm{~b}$ ).

\subsubsection{Storm surge and river floods}

In the Caribbean, Haiti, Jamaica and the eastern part of Cuba were affected by flooding and debris flow caused by heavy precipitation. For example, the Croix de Mission River flowing through Port au Prince in Haiti rose to threatening levels for the adjacent housings.

On the US East Coast, the huge extent of the hurricane led to storm surges caused by storm winds that advanced from south to north along the affected coastlines of Virginia, Delaware, New Jersey, New York, Connecticut, Rhode Island and Massachusetts. As shown in Fig. 4d, the storm surge at the Chesapeake Bay Bridge Tunnel Gauge occurred twelve hours (equivalent to one astronomical tide) before the highest water levels in New York (Battery gauge, Fig. 4c). North of the storm center, hurricane-force winds had an east to west (landward) direction (wind gusts of up to $130 \mathrm{kmh}^{-1}$ ) and caused the extreme water levels seen along the coastlines from New Jersey to Massachusetts. The impact and magnitude of the storm surge in the affected area differed due to the bathymetric and geographical characteristics and a complex interplay of spatio-temporal factors. In New York City and on Long Island, the storm surge was most extreme: measurements from New York City show that the shift in the wind direction, minimum sea level pressure accompanied by maximum gusts, and the full moon high (astronomical) tide occurred at the same time: around 01:00 UTC on 30 October (Fig. 4a-c). This superposition of effects did not happen to the full extent at other locations of the affected coastal areas.

Fluvial river flooding due to high precipitation amounts was recorded at several gauges that are spatially clustered in the Potomac and upper Susquehanna river basins as well as the tributaries of the Delaware River in the area of Philadelphia. These river basins cover large parts of the federal states of Pennsylvania, Maryland and Delaware. Further, two gauges at the Hudson River reported flooding. The runoff response is determined by the interplay of diverse hydrological processes depending on geomorphological catchment characteristics and conditions. In this specific event, the occurrence of snowfall in the Appalachian Mountains resulted in a temporary storage of water in the headwater regions of the river systems and thus attenuated the runoff response. Furthermore, the initial flow conditions had been much below normal flow. For instance, in the Potomac River at the gauge Point of Rocks (Fig. 4f), the flood wave started from 

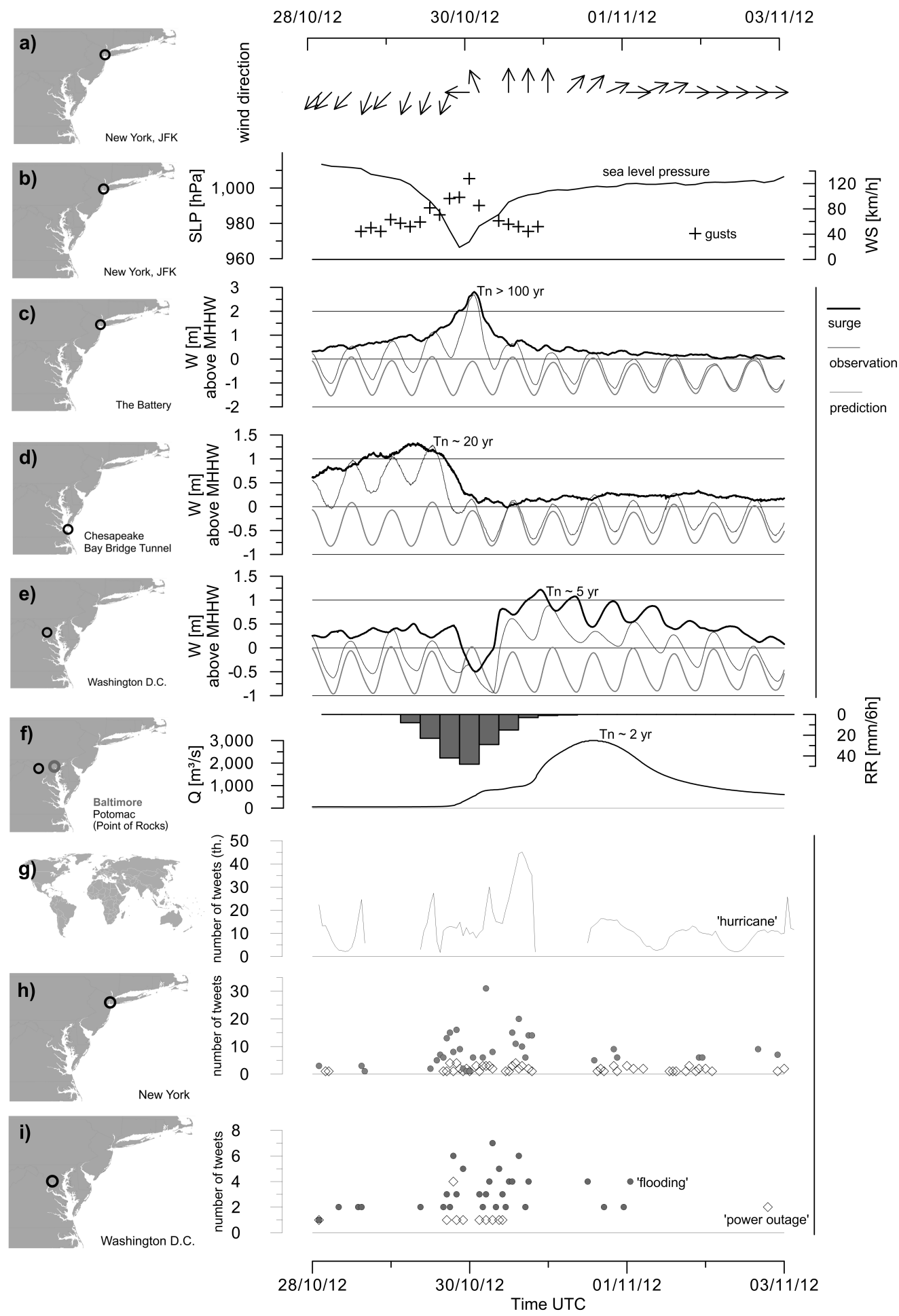

Fig. 4. Evolution and magnitude of the hazardous effects and twitter response associated with the landfall of Hurricane Sandy in the US. From top to bottom: (a) wind direction and (b) peak gusts with sea-level pressure at JFK Intl. Airport; storm surge at the tidal gauges of (c) New York, (d) Chesapeake Bay Inlet and (e) Washington DC NOAA (2012; http://water.weather.gov/ahps); (f) precipitation at Baltimore/Washington Intl. Airport and discharge of the Potomac River at Point of Rocks USGS discharge gauges (2012; http://waterwatch.usgs.gov/index.php; (g) worldwide twitter response with the keyword hurricane; (h) localized twitter responses with the keywords flooding and power outage in New York; (i) same as (h), but for Washington DC. 
a discharge of around $60 \mathrm{~m}^{3} \mathrm{~s}$, which was very close to the flow value that exceeded $90 \%$ of the time (USGS, 2012).

At lower reaches of the rivers or in estuaries near the Atlantic, high water levels cannot be attributed to single trigger mechanisms. Rather they were caused by the superposition of tidal currents, storm surges and fluvial flooding associated with heavy rainfall. For the tide gauge of Washington DC, for example, the influence of tidal dynamics and storm surge is obvious in the time series shown in Fig. 4e. This gauge is situated remote from the coast at the mouthing of the Potomac River. The maximum water levels during this event were reached a full $36 \mathrm{~h}$ after the high tide at the Chesapeake Bay Bridge Tunnel (Fig. 4d). This is due to the propagation of the surge along the Chesapeake Bay. Further, the water levels remained at a high level during the 31 October and 1 November. The superposition with the inland flood wave flowing off from the Potomac River basin (Fig. 4f) contributed to this effect.

In order to assess how the peak coastal water levels and river discharges recorded during Sandy compare to the past, their recurrence intervals ( $\mathrm{Tn}$ ) using extreme value statistics were quantified. For this purpose, annual maximum series (AMS) for the different USGS (2012) discharge gauges (http://waterwatch.usgs.gov/index.php and NOAA (2012) tidal gauges (http://water.weather.gov/ahps) were obtained and analyzed statistically. As several probability distribution functions may satisfactorily describe the AMS data variability, our assessment was based on a composite distribution function approach (Apel et al., 2006; Wood and RodriguezIturbe, 1975). The composite function resulted from weighting the distribution functions based on likelihood weights. Note that at the given point of time all observations considered in this paper are provisional data and subject to revision.

Observed water levels at the tidal gauges from northern Virginia to Rhode Island exceeded recurrence intervals ( $\mathrm{Tn}$ ) of $10 \mathrm{yr}$. The highest levels, corresponding to a $\mathrm{Tn}>100 \mathrm{yr}$ event, occurred at the tidal gauge at Battery on the southern tip of Manhattan, where water levels unprecedented in the record occurred due to the concurrence of the aforementioned reinforcing effects. Specific flow characteristics at this gauge, namely the confluence of Hudson and East rivers at the northern end of Upper Bay may also have contributed to the record water level. At Kings Point in the Long Island Sound and at the Chesapeake Bay Bridge Tunnel gauge (Fig. 4d), for example, the effects of the storm tide maxima were pronouncedly lowered by the low (astronomical) tide, but still reached levels of $\mathrm{Tn}=20 \mathrm{yr}$ and more.

By contrast, recurrence intervals of peak discharges at locations off the coast were substantially lower. For example at the streamflow gauge Point of Rocks at the Potomac River (Fig. 4f), $\mathrm{Tn}=2 \mathrm{yr}$ was quantified. Other gauges showed slightly higher levels, for example, Tn of $4 \mathrm{yr}$ has been estimated for the peak discharge at the gauge East Branch Brandy Wine Creek below Downington and a Tn of $6 \mathrm{yr}$ for the Monocacy River at Jug Bridge near Frederick. In general,
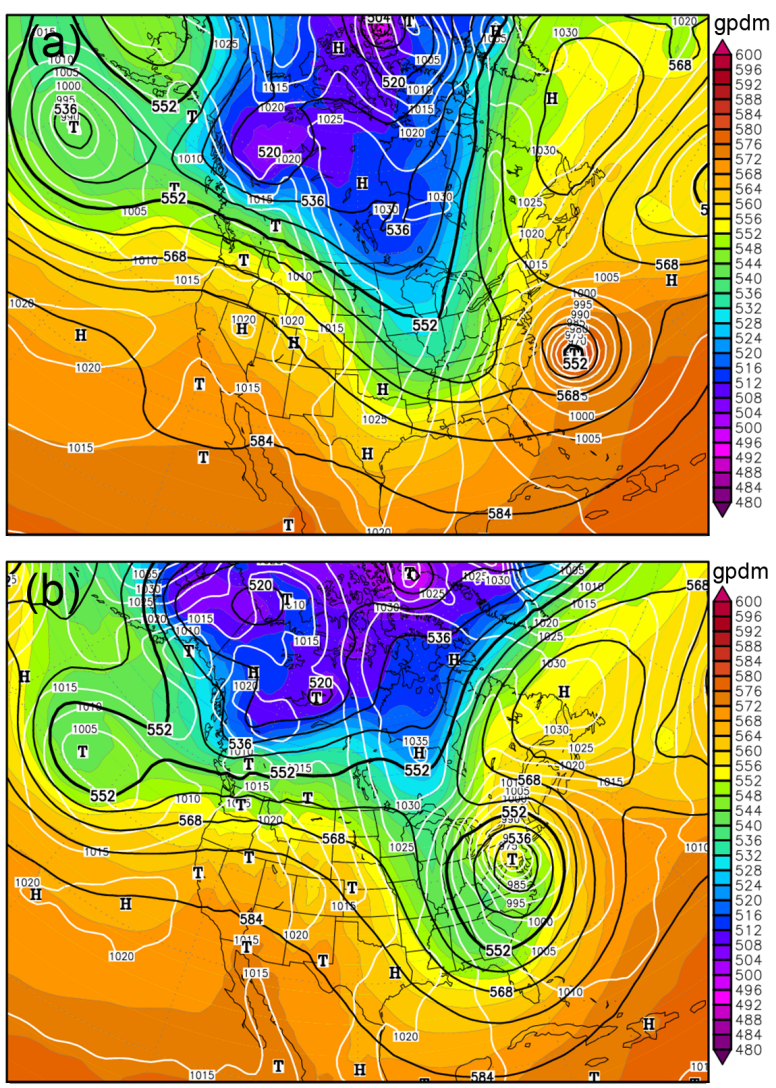

Fig. 5. Weather charts for 28 October, 18:00 UTC (a) and 30 October, 06:00 UTC (b) with $500 \mathrm{hPa}$ geopotential height (black lines), surface pressure (white lines) and $1000 / 500 \mathrm{hPa}$ relative topography (colors) from the Global Forecast System (GFS). Image credit: wetter3.de.

the observed peak flows rather correspond to frequent flood events. Reports of extensive inundation of structures and roads, significant evacuations of people and/or transfer of property to higher elevations were only on a local level.

\subsection{Extraordinary event and multihazard characteristics}

Sandy was a late and strong hurricane in the Caribbean, which, however, is a hurricane-prone region. In contrast to this, the US East Coast has rarely been afflicted by hurricanes in the past. Since recording, Sandy was only the third hurricane that made landfall in New Jersey. According to the Hurricane Probability Project (Colorado State University; http://typhoon.atmos.colostate.edu), the probability of landfall in New Jersey is only 1\% during a hurricane season, whereas, for example, in Florida this probability is $51 \%$. For other states on the US East Coast that have been affected by Sandy (e.g. Delaware, Virginia, New York), the probability is between 1 and $8 \%$. 


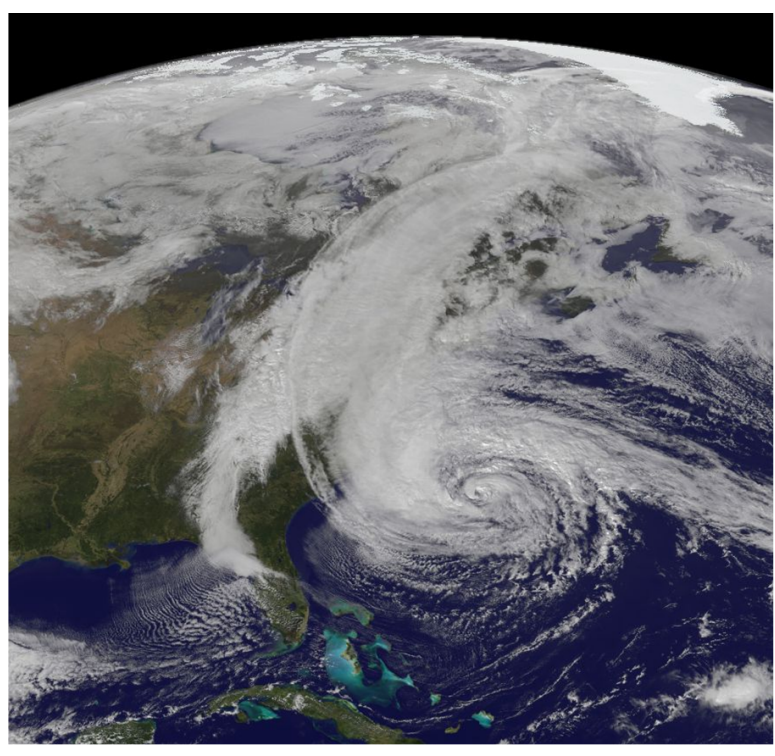

Fig. 6. Satellite image on 28 October 2012, 17:45 UTC. Image Credit: NASA GOES Project.

Unusually high sea surface temperatures, which were well above average along the track of Sandy, helped to keep the intensity over several days. The deviation from the long term average sea surface temperature was $2-4 \mathrm{~K}$ on 27 October off the East Coast of the US. The warm water provided more latent heat, which is the source of energy for hurricanes, and intensified the TC while there was no or only little vertical wind shear, which is destructive for those systems.

Nearly all tropical cyclones in the North Atlantic turn onto an east-northeasterly track before they get anywhere close to the US. mainland. Afterwards, they usually travel towards Europe as extra-tropical cyclones. However, the particular meteorological situation over the North American continent and the Atlantic Ocean from 28 October onwards led to a significant shift of Hurricane Sandy. By the end of October, an unusually well-pronounced upper air ridge (high pressure at higher levels in the troposphere) established over eastern Canada. In cooperation with a North Atlantic low pressure system, the ridge had a blocking effect to Hurricane Sandy, which was on the way from the southwest. The usual right turn, referred to as recurvature, was not possible for Sandy. Thus, the storm was forced towards the west-northwest and targeted New Jersey and New York.

Sandy interacted with a huge upper level trough that stretched across the central portion of the US and moved into an easterly direction (see Fig. 5). At its eastern edge the trough provided additional forcing and extra lifting of the warm and moist tropical air, which resulted in a further strengthening of the storm system. The satellite image from 28 October 2012, 17:45 UTC (Fig. 6) shows the elongated cloud band of a cold front ahead of the upper level trough; the frontal clouds reach from central Florida along the Appalachian Mountains into the north-eastern US. An extended shield of high-level clouds aloft indicates the strong south-westerly flow and the lifting forces that are already active between the Great Lakes and the Atlantic coast. While approaching the trough, Sandy grew rapidly; temporarily the storm had a horizontal extension of record breaking $1700 \mathrm{~km}$. Even far from the center, storm force winds occurred, which, for example, caused wave heights of up to $6.6 \mathrm{~m}$ in Lake Michigan.

A perfect timing just before landfall initiated the transition from a tropical into an extra-tropical cyclone: On 28 October, 18:00 UTC, Sandy still showed an approximately symmetric warm core, which is a characteristic feature of TCs. Within the next $36 \mathrm{~h}$, the intrusion of cold air began to evolve warm and cold fronts, whereas the core became colder and asymmetric, which is characteristic for extra-tropical cyclones. Shortly after landfall, Sandy turned into a cold-core low and completed the extra-tropical transition. With both tropical and extra-tropical characteristics during landfall, Sandy became somewhat capricious and dangerous (see Fig. 5).

The date Sandy made landfall is well outside the peak hurricane season, especially as far north as New York. Cold air advection from Canada included into Sandy's circulation provided the potential for blizzard-like weather conditions in parts of the Appalachians, where snow accumulations were nearly $1 \mathrm{~m}$ in some areas.

\section{Impact of Sandy in the Caribbean}

\subsection{Social impacts}

Cuba and Haiti were the hardest hit countries in the Caribbean in terms of number of affected people. During the passage of Sandy on 25 October (see Fig. 1), at least 80 people were killed in the Caribbean, with highest death tolls in Haiti (54 or more killed, 15 missing; OCHA, 2012b, c; ECHO, 2012). In Cuba, eleven people died and 3 million people suffered direct or indirect impacts (IFRC, 2012b; OCHA, 2012a). Overall, 243000 houses and 2601 schools were damaged or destroyed by strong winds as well as flooding; 615 health centers were damaged or impaired in their functioning (see also Sect. 4.2). Access of an estimated number of 1 to 1.5 million people to safe water was hampered (IFRC, 2012b; ECHO, 2012). Wind, heavy rainfall and subsequent overflowing of rivers in the west and southwest of Haiti killed at least 54 people, destroyed or damaged 27000 houses and emergency shelters of 5298 families; 50 schools were destroyed and 100 damaged. With 100000 ha of destroyed crops by the strong winds in Cuba and 90000 ha of devastated cropland by heavy rain and flooding in Haiti, in both countries the risk of food insecurity has severely increased and is expected to also have a medium-term effect on livelihoods (IFRC, 2012b). 

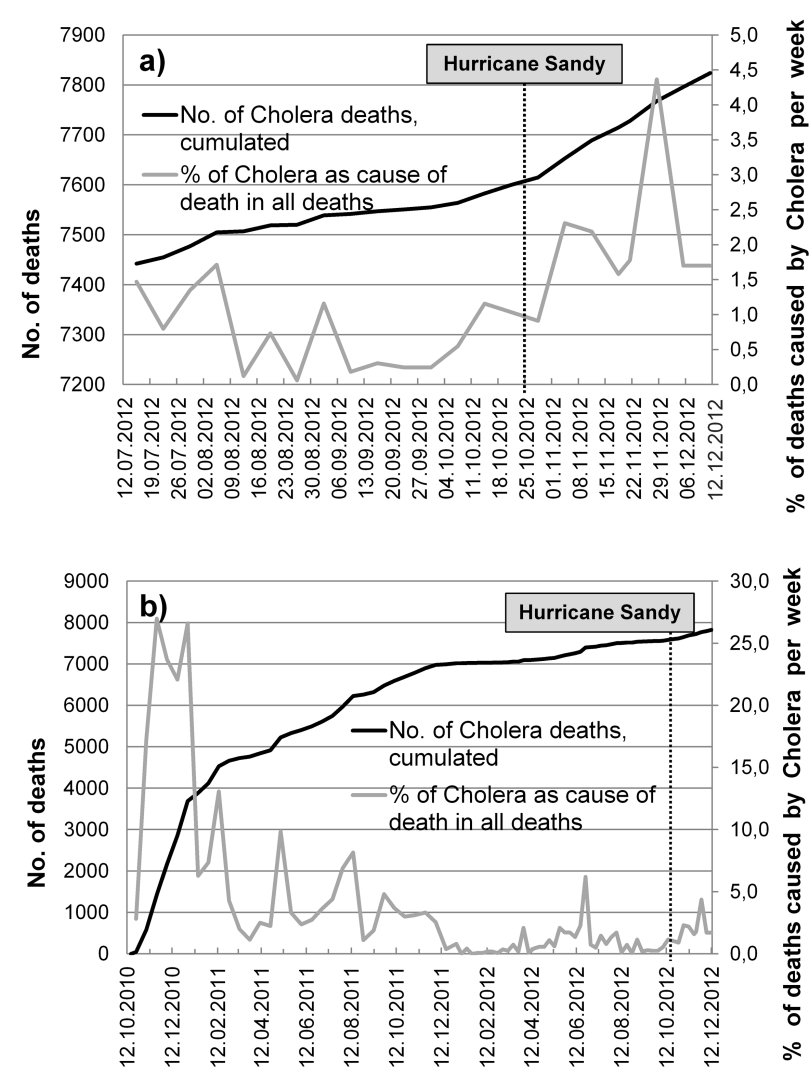

Fig. 7. Number of cumulated cholera deaths per week and percentage of cholera as death cause out of all deaths per week in Haiti (a) during the four months before and the seven weeks after Hurricane Sandy, and (b) from 17 October 2010 to 12 December 2012. Data: Ministère de la Santé Publique, Republique d'Haiti and CATDAT Database

Even if Sandy historically was not the deadliest hurricane affecting Haiti (see Mühr et al., 2012), there are some factors that aggravate Sandy's impact in Haiti. Firstly, Hurricane Sandy struck a country that is still recovering from the devastating earthquake in 2010 with 350000 people still living in camps for internally displaced persons (OCHA, 2012c). Secondly, after the passage of Hurricane Isaac in August 2012 and Hurricane Sandy in October 2012 resulting in destruction of agricultural crops in at least 60 communities, 450000 to 1.5 million people are at an increased risk of malnutrition (OCHA, 2012c, d; CDEMA, 2012; ECHO, 2012). Thirdly, damage to medical facilities (including 22 cholera treatment centers), problems in restocking because of interrupted transportation, and poor sanitary conditions have increased the risk of waterborne diseases such as cholera. After the cholera outbreak in October 2010 in the aftermath of the major earthquake in January 2010, cholera is still prevalent in Haiti, yet was declining in terms of new cases and deaths in the months before Hurricane Sandy. Figure 7 shows the cumulated absolute number of cholera deaths over time

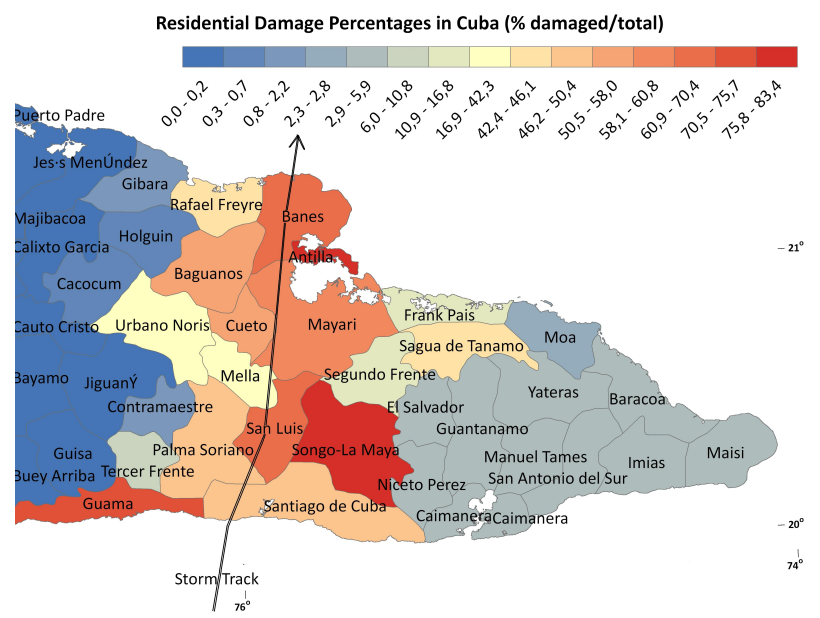

Fig. 8. Residential damage in Cuba as a percentage of housing stock using data from (Daniell, 2012; IFRC, 2012a).

and the percentage of weekly cholera deaths since the epidemic outbreak in October 2010. In the first seven weeks after Sandy, approximately 22000 new cases and 209 deaths were reported (Ministère de la Santé Publique, Republique d'Haiti), which represents a slight increase in disease spread, compared to the weeks before, both for cholera deaths and new cases. Comparing the current increase in cholera deaths after Hurricane Sandy with the progression of the epidemic since its outbreak, it can be seen that the current increase is still rather small compared to the peaks during the initial outbreak phase and also smaller than the peak in June 2012 when cholera had already started to decline.

\subsection{Economic impacts}

Direct losses in the Caribbean have been extensive on a GDP comparison for nations (see Table 2). The estimation of losses listed in Table 2 was undertaken using analysis of destroyed and damaged buildings in addition to other sectoral losses such as agriculture, infrastructure, education and health as a proportion of capital stock and GDP as reported from Daniell et al. (2011) and in the CATDAT database (Daniell, 2012). Loss functions were developed based on previous damage seen in previous impacts of hurricanes in Cuba, Haiti and the rest of the Caribbean as a function of wind speed, storm intensity and flooding as well as the current damage reported from the International Federation of Red Cross and Red Crescent Societies (IFRC) and national agencies.

According to this analysis, losses were greatest in Cuba with around $5.5 \%$ of GDP where over 226000 houses were damaged and 17000 destroyed (Fig. 8). The damage followed the storm track closely, with over $20 \%$ of houses losing roofs due to the high wind speeds. Flooding was also widespread. In some sections of the Holguin and Santiago 
Table 2. Direct economic loss estimates for the Caribbean and the US.

\begin{tabular}{llll}
\hline Country & $\begin{array}{l}\text { Estimates loss } \\
\text { (million US\$) }\end{array}$ & \% of GDP & Source \\
\hline Cuba & 3380 & 5.5 & CEDIM \\
Haiti & $>280$ & 3.8 & CEDIM \\
The & $300-400$ & $3.7-4.9$ & CCRIF \\
Bahamas & & & \\
USA & $78000-97000$ & 0.5 & CEDIM \\
Jamaica & 66 & 0.4 & Jamaican \\
Dominican & 85 & 0.14 & Govt \\
Republic & & & CEDIM \\
Canada & $>100$ & 0.0057 & Jamaican \\
& & & Govt \\
Bermuda & minor & & \\
\hline
\end{tabular}

de Cuba provinces, the percentage of damaged buildings reached over $80 \%$ as compared to the total building stock estimated from the changes from last census. Some of this was related to the vulnerability of building stock, yet some to variable wind speeds and flooding from storm surge (as seen in Guama) and rainfall (seen in Songo-La Maya).

In addition, much damage to schools, agriculture (sugar cane, bananas) and the power systems occurred. However, this has not been the largest economic loss due to hurricanes in Cuba, as over USD 8 billion damage occurred through Hurricane Ike in 2008.

Haiti has also seen major damage through the combination of river flooding and pluvial flash flooding with over 6000 buildings destroyed and 21000 buildings damaged, and The Bahamas also saw major damage with both countries having losses equivalent to around $4 \%$ of GDP.

\section{Impacts of Sandy in the US}

\subsection{Impacts on life}

In the eastern US, 142 people died because of Sandy, most of them in New York, New Jersey and Pennsylvania. Of the 64 fatalities in the state of New York, 43 occurred in New York City (NYC) 22 of which were on Staten Island (Reuters, 16 November 2012, and Keller in NY Times, 17 November 2012). Comparing the hurricane fatalities in the states New York, New Jersey and Pennsylvania with historic events (see Table 3), it can be seen that Sandy is among the three most fatal events of recorded history of hurricane deaths. For New Jersey, it is the deadliest single TC event ever.

\subsection{Impacts on infrastructure: cascading effects}

Energy systems are amongst the most important critical infrastructure due to their essential role in sustaining

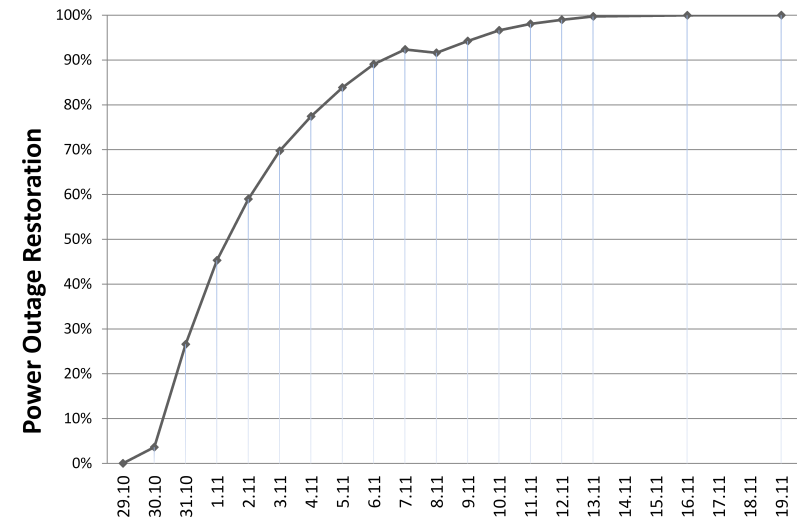

Fig. 9. Timeline of restoration of power outage from Hurricane Sandy between 29 and 30 October and the nor'easter on 7 November for affected customers in the US (Customer outages are compiled from specific situation reports obtained from the US Department of Energy, Office of Electricity Delivery and Energy Reliability from 29 October to 19 November).

socioeconomic systems. As a part of physical infrastructure (including services), they are directly vulnerable to natural disasters. As they are highly interconnected, the consequences of disruptions may propagate widely (Rose et al., 1997). A combined total of around 21.3 million people (8.7 million customers) were left without power from peak outages of Hurricane Sandy on 29 and 30 October, but also from the subsequent nor' easter storm on 7 November (DOE, 2012a, b). Power outages stretched across 21 states from western Indiana to northern Maine, and affected residents of some of the most populated cities in the US, including NYC (in particular the lower part of Manhattan). Using data available from the US Department of Energy (DOE, 2012a, b), Fig. 9 shows the three-week timeline of power outages from the peak outage (29 October) to the recovery (19 November). One week after impact, $84 \%$ of the energy system had been restored. However, about 3.37 million people (mostly in New York and New Jersey) were still waiting for electricity supply. On 7 November, a nor'easter storm began to impact the Mid-Atlantic and Northeast bringing additional power outages to 368000 people. However, despite widespread power outages after Hurricane Sandy, the duration of these outages was not unusually long in comparison to other major hurricanes in the US. It took utility companies 13 days to restore power supply to $95 \%$ of customers. Hurricanes Katrina, Rita and Wilma in 2005 and Ike in 2008 all resulted in longer outages for customers in Louisiana (18 days for Katrina), Texas (23 days for Katrina), Mississippi and Florida (Fahey, 2012). The longest stretch to $95 \%$ restoration since 2004 was 23 days after Hurricane Katrina.

Nevertheless, nearly two weeks without electricity, heat and other provisions exceed the limits of most citizens' capacities to manage their everyday lives. The situation 
Table 3. Number of storm fatalities in the states New York, New Jersey and Pennsylvania from historic hurricane/storm events. Sources: Reuters, 16 November 2012, Keller in NY Times, 17 November 2012, and Daniell (2012).

\begin{tabular}{lrcrcrc}
\hline & New York & & New Jersey & \multicolumn{2}{c}{ Pennsylvania } \\
Rank & Storm Name, Year & Deaths & Storm Name, Year & Deaths & Storm Name, Year & Deaths \\
\hline $1^{*}$ & Sandy, 2012 & $\mathbf{6 4}$ & Sandy, 2012 & $\mathbf{3 7}$ & Diane/Connie, 1955 & $75-90$ \\
1 & New England, 1938 & 60 & Unnamed, 1806 & 21 & Agnes, 1972 & 50 \\
3 & Edna, 1954 & 29 & Irene, 2011 & 10 & Sandy, 2012 & $\mathbf{1 3}$ \\
4 & Norfolk/Long Is., 1821 & 17 & Unnamed, 1944 & 9 & Floyd, 1999 & $6-13$ \\
5 & Hurricane Five, 1894 & 10 & Unnamed, 1878 & 8 & Gale of 1878 & 10 \\
6 & Agnes, 1972 & 6 & Floyd, 1999 & 6 & TC Allison, 2001 & 7 \\
\hline
\end{tabular}

* The New England Storm 1938 and Sandy 2012 are deemed to be equally ranked as the fatality numbers for the New England Storm 1938 did not include indirect deaths whereas the numbers for Hurricane Sandy include indirect deaths via carbon monoxide poisoning, debris removal, etc.

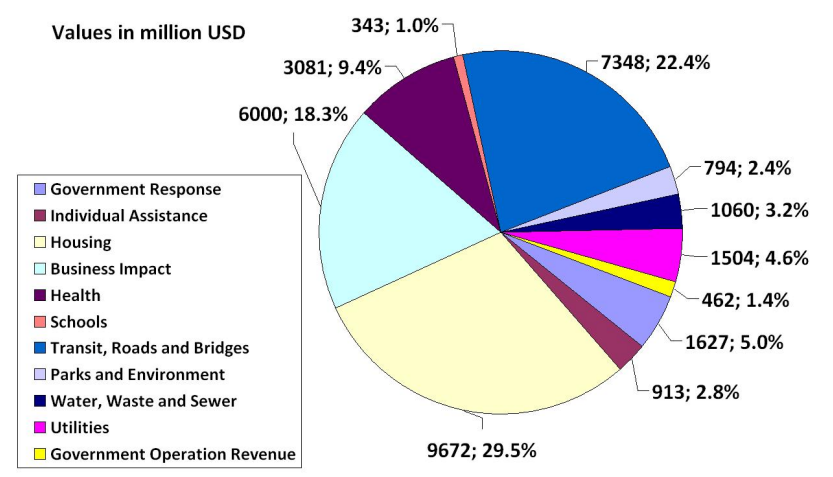

Fig. 10. A breakdown of direct losses in New York State (in million US\$ and \%) reported by (Cuomo, 2012).

imposed a particularly severe hardship on the sick, elderly, handicapped and poor. Since there is only limited data available on the consequences of power outages caused by TCs, an empirical comparison is difficult. The affected people rely on electricity and are heightened exposed to risks from fire and carbon monoxide poisoning as people use generators, or other gasoline-, propane-, or charcoal burning devices inside their homes for heating, and observed in former comparable incidents (Platz et al., 2007).

The main reason for fires following hurricane is usually electrical system failures and wiring issues caused simply by the wind speed being too high for the intended safety factor associated with this infrastructure. In a fire in Breezy Point, Queens, in New York during Hurricane Sandy, 111 houses were destroyed and 20 damaged (Trapasso, 2012). Numerous other dwelling fires occurred in other states. In total, over USD 60 million damage can be attributed to fire in New York alone. Historically, Hurricane Katrina showed the large impact of fires following hurricane, where due to evacuations, fires were able to spread uncontrolled through poorer parts of the city. Hurricane Irene in 2011 also caused many electrical fires (Daniell, 2012). Models for fire following hurricane are currently limited to poorly validated probabilistic relations between number of outbreaks, TC wind loads damage before

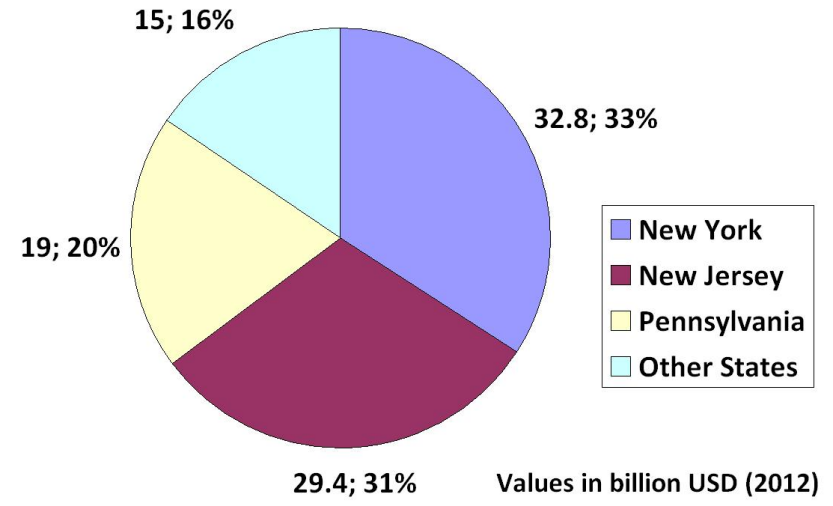

Fig. 11. Direct economic losses (in billion US\$ and \%) by US states from Hurricane Sandy.

fire, wind speeds, and the level of preventive fire protection standards.

In tall apartment buildings and commercial skyscrapers, lack of elevator service poses a serious problem for the disabled or elderly who cannot navigate stairs. The combined power outage and severe weather conditions due to winter storms, further stresses the affected population. Threats from water and food shortages, food poisoning from refrigeration not working, disease outbreaks from malfunctioning sewage systems/drinking water supply and deficits in health care can become serious issues (Bayleyegn et al., 2006). Although there was no gas shortage through resource depletion, the lack of electricity prevented filling stations from dispensing fuel, resulting in long queues and rationing.

\subsection{Estimation of direct losses}

Early estimates of direct economic losses from risk modelling firms such as EQECAT and AIR were in the order of USD 20-50 billion but turned out to be lower than the final total.

New York direct losses have totalled around USD 32.8 billion for repairs and restoration (Fig. 10; Governor Andrew 
Table 4. Direct economic losses by historic hurricanes that have affected the US.

\begin{tabular}{lc}
\hline Hurricane (Year) & $\begin{array}{c}\text { Direct Economic Losses in the US } \\
\text { (in billion US\$ 2012) }\end{array}$ \\
\hline Katrina (2005) & 127.8 \\
Sandy (2012) & $\mathbf{7 8 - 9 7 *}$ \\
Andrew (1992) & 42.7 \\
Ike (2008) & 31.3 \\
Wilma (2005) & 23.9 \\
\hline
\end{tabular}

* refers to the loss estimation by CEDIM (CATDAT Database Daniell, 2012).

Cuomo). An estimated 305000 houses were damaged or destroyed in New York state as of 26 November 2012, causing around USD 9.7 billion in damage. The other relative components of the loss estimate by the government are shown in Fig. 10 (Cuomo, 2012). This is related to the massive exposure located in this region of the US with New York and New Jersey combining to have over USD 5 trillion capital stock. In addition, over 265000 businesses were affected. New York City has stated that the economic losses due to direct causes have totalled USD 13.3 billion, and indirect causes from USD 5.7 billion (DeStefano, 2012). The losses provided by Cuomo (2012) were slightly higher totalling over USD 15 billion for New York City (about $2 \%$ of the gross city proper product).

New Jersey has released losses to housing, transit systems, infrastructure, tourism and coastlines at USD 29.4 billion (Fig. 11). Damage before this was quoted as being $34 \%$ from New York, $30 \%$ from New Jersey, $20 \%$ from Pennsylvania and $16 \%$ from remaining states using the EQECAT estimate. Using this total system, losses in Pennsylvania would hit around USD 19 billion, with an additional USD 15 billion from other states, leaving a total of USD 97 billion damage from this event, given the fact that New York and New Jersey loss estimates have fitted this model well.

In addition, indirect losses (see Sect. 5.4) could contribute to additional losses on top of the USD 97 billion estimated damage, and indirect losses may already be included to some extent in the business impact in New York and tourism estimate in New Jersey, thus a reduction of $20 \%$ and a range of losses is proposed from USD 78-97 billion for the direct loss estimate (see Table 4). This would make Sandy the second highest economic loss from a US hurricane in history and the highest worldwide loss from a natural disaster event since the Tohoku earthquake in March 2011 (Daniell et al., 2011).

Indirect losses are generally high in productive locations such as New York City. They are scrutinized in the following Sect. 5.4.

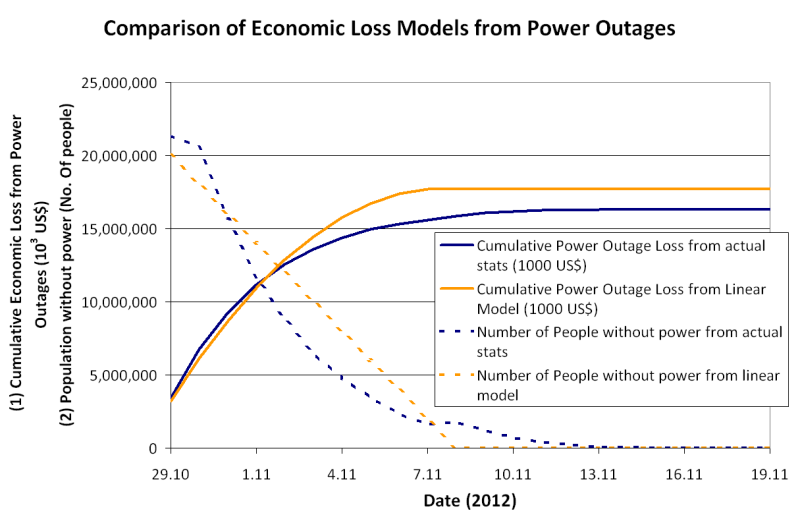

Fig. 12. Economic loss from power outages.

\subsection{Estimation of indirect losses}

Besides direct costs due to damage of physical infrastructure, natural disasters often result in important indirect losses that have grown considerably due to the increasing interrelatedness of globalized supply networks and the growing dependence of modern societies on critical infrastructure (Kleindorfer and Saad, 2005; Comes and Schultmann, 2012; Perrow, 1984). Indirect economic losses are caused by the disruption or failure of physical or economic linkages (PenningRowsell et al., 2003; Messner et al., 2007). Particularly the interruption of the most essential infrastructure such as electric power (cf. Sect. 5.2) or transportation can cause cascading effects throughout further infrastructure systems (Rinaldi et al., 2001). In the aftermath of a natural hazard, the greatest share of indirect losses results from business interruption (Tierney, 1994), especially due to the decline of production resulting from destroyed infrastructure and associated supply chain disruptions (Zimmerman and Restrepo, 2006).

To estimate the indirect losses, two approaches were used: an estimation of the costs of the power outages based on a comparison with previous events and an estimation of the indirect based on a sector-specific model that takes into account the indirect vulnerability of industrial sectors due to business interruption using an input-output model (I-O model) approach.

\subsubsection{Estimation based on past events}

The total costs (direct and indirect) of blackouts can be roughly estimated based on a comparison with similar past events. The losses of previous power blackouts have been compared, including events that were not caused by disasters. For instance, the costs of the 2003 Northeast blackout, which affected 55 million people, particularly throughout the northeastern states of the US, were estimated to be about USD 6.3 billion. With close estimates of USD 5.6 billion for one day, Zimmermann et al. (2005) demonstrated the 
possibility to estimate costs based on GDP per capita and the number of people affected.

A similar approach is used to assess the costs for the power outages that occurred in the aftermath of Sandy. The GDP per capita per day averaged from Pennsylvania, New York and New Jersey is USD 160.89. Using a linear recovery function from 20 million people affected on Monday, 29 October, to 2 million on Wednesday, 7 November, losses are about USD 3.22 billion for the first day, and USD 17.7 billion for the first ten days of power outages. Using the current statistics of power outages as portrayed in Fig. 12 and discussed in Sect. 5.2, the value of power outage disruption is USD 16.3 billion.

\subsubsection{Estimation of economic losses due to business interruption (I-O modeling)}

The rapid assessment of indirect losses requires robust methods that work with limited and incomplete data. At the same time the methods must allow for comparisons with previous disastrous events, occurring in countries of different sizes, development levels and economic power. Given those requirements, a methodology was chosen based on inputoutput data available from the national statistical offices of each state. Indirect economic losses are usually quantified in terms of production losses in the affected region with the help of input-output models (Okuyama, 2007). Such an approach is based on a national account's input-output matrix which represents monetary transaction flows between the various industry sectors. Based on an inverse matrix according to Leontief (1986), the output loss resulting from the interruption of a specific sector as well as its indirect effects is quantified by considering the inter-industrial linkages and dependencies.

For the estimation of indirect losses, the focus was on the assessment of business interruptions in the manufacture sector because most of the economic losses due to business interruption occurred in this sector (Chang et al., 2007). Furthermore, the 14 northeastern states which were exposed to Sandy play a key role for the manufacturing sector, accounting for $26.5 \%$ of the added value created in this sector in the whole US economy. Figure 13 shows, for each industry sector, the share of the US value added created in the northeastern states.

As can be seen, the affected region is particularly important for the chemical industry, the apparel and leather and allied products, textile mills, etc. Since most businesses were interrupted at least on the day of Sandy's landfall, this gives a first idea of the extent of output losses on this day for the US economy. Under the assumption that the industry lost two days affecting on average $26.5 \%$ of the US manufacturing sector (corresponding to the sector's value added in 14 northeastern states), the resulting net losses in terms of lost output would amount to USD 2.39 billion. Nevertheless, the estimation of losses must also take into account the ripple effect resulting from supply chain disruptions into other sectors of the economy. Using a linear input-output model (Leontief, 1986) to calculate those indirect effects, the losses would approximate USD 9.4 billion for two days' business interruption.

Using a linear I-O model (Leontief, 1986), the potential impacts of Sandy on different business interruption scenarios of the US economy were estimated. The model describes inter-industry relationships within the economy, where the output from one sector is defined by the production that may become input for another sector. In our approach, the input of the model is accounts data (year 2010; annually published by the Bureau for Economic Analysis) describing the monetary interactions between the various sectors on the US national level. Based on these industrial interrelations, it is possible to quantify the total loss caused by the decrease or interruption of a sector's production including its indirect repercussions on the entire industrial production chain. To estimate the extent of the production losses, a production loss ratio is determined for each sector, which depends on affected geographic area, intensity and duration of the interruption. For the purposes of our near-real-time analysis, we primarily assumed that the direct damage in the aftermath of Sandy affected all industry sectors equally for all of the 14 affected coastal states (Connecticut, Delaware, Maine, Maryland, Massachusetts, New Hampshire, New Jersey, New York, North Carolina, Ohio, Pennsylvania, Rhode Island, North Dakota and Vermont). Afterwards, we determined for each sector which proportion of the national production originates from each of the 14 states (through percentage of value added originating in affected states) and was affected by disruptions or interruptions of a certain intensity.

In an additional worst case scenario, we assumed that all production activities of the manufacture sector were entirely interrupted during two days for all of the 14 states. Under this assumption, and using the linear I-O model (Leontief, 1986) to calculate the indirect effects, the losses were estimated to be approximately USD 9.4 billion for two days of business interruption. Of course, this estimation can only be considered as an upper limit.

With a similar input-output approach, Moody Analytics calculated a net loss output of USD 10.5 billion due to Sandy. These estimations were calculated for the disruptions in all sectors of the economy, and for the regions worst impacted by Hurricane Sandy, i.e. Bridgeport, New York City, New Jersey, New York City, Philadelphia, and Washington. These estimations were completed using the IMPLAN regional multiplier (Alward et al., 1992), which simulates the induced effects on the regional economies, including on employment and final consumption. The resulting indirect losses correspond to a total lost output of approximately USD 19.9 billion.

The extent of business interruption, their effects on different industrial sectors, as well as the costs generated depend on other factors, such as the duration of the hazard event and 


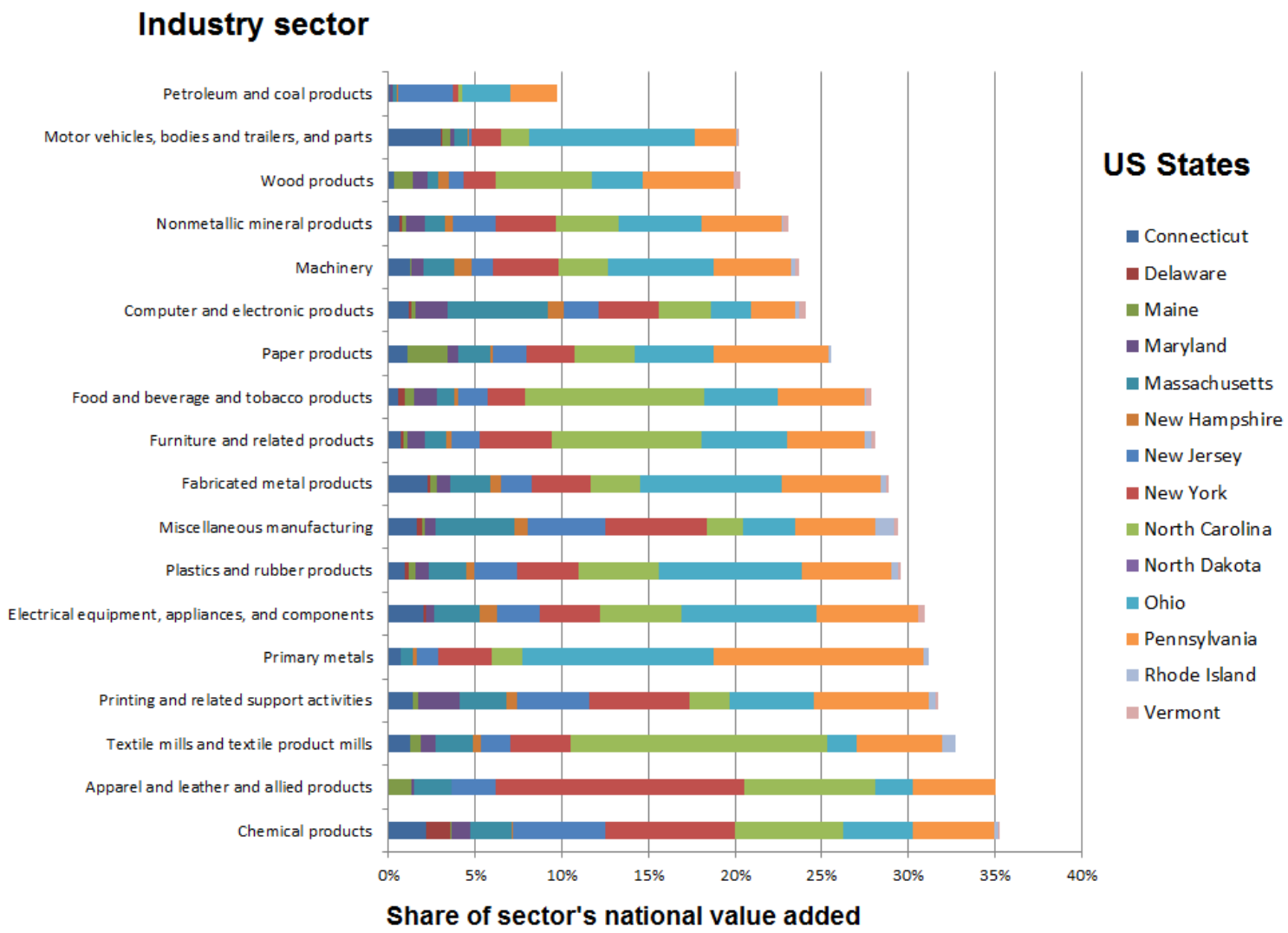

Fig. 13. Share of sectors' value added in affected states compared to the US economy.

the recovery time (Webb et al., 2002), as well as the vulnerability of the industry sector. In order to take these factors into account, a simple input-output analysis coupled with an assessment of the industrial vulnerability was used which tested different scenarios of recovery and business interruption duration. The vulnerability of the affected industry determines the capacity of businesses to cope with the impacts of disasters and interruption and to restart their businesses after a disaster, and therefore influences indirect losses. As different industrial sectors vary greatly with respect to their characteristics (such as dependence on critical infrastructure or further industrial sectors, labor dependence etc.), the vulnerability of industrial production systems strongly depends on the type of industry affected.

In order to assess the sector-specific vulnerability, an indicator-based approach was used for its transparency and operational representation of vulnerability (Cutter et al., 2003). Additionally, due to their hierarchical structure, indicator approaches are suitable for (near) real-time disaster assessments as they enable the efficient update of information as revisions of information only in the affected branches are required (as opposed to a complete update). Moreover, newly available information can be added in terms of further branching (e.g., higher level of detail by the integration of information about specific production sights). For the generic assessments in the early phases after the incident, considerations remained on the sectoral level. Production downtime mainly occurs due to the damage of production equipment, the obstruction of workers, the interruption of critical infrastructure or the disturbance of supply chain processes (e.g., delivery or distribution processes). Therefore each sector's specific vulnerability against indirect disaster effects can be determined with the help of vulnerability indicators describing its degree of dependency on capital, on labor, critical infrastructure systems and its connectedness in supply chains (Merz, 2011). The sector specific vulnerability was calculated based on 17 indicators. These were based on nationallevel data from 2011, including input-output tables and other data obtained from the US Bureau of Economic Analysis.

Figure 14 shows the industrial vulnerability against indirect disaster effects at the state level. It can be seen on the map that from the northeastern states, the most vulnerable states are Maine, Virginia and North Carolina. It can therefore be assumed that these states are the most vulnerable against business interruption. However, the extent of losses also depends on the direct damages caused by the storm in affected states. (Note that vulnerability is not the only dimension of risk; further components determining the actual losses refer to the extent and severity of the hazard itself.) 


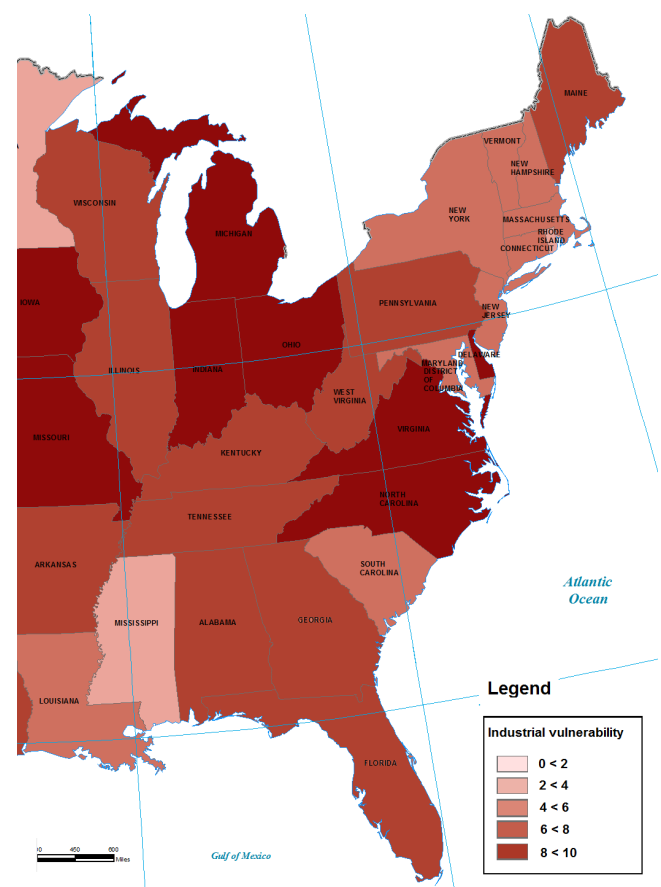

Fig. 14. Industrial vulnerability of the eastern US against indirect disaster impacts (to obtain those results, the sector specific vulnerability was regionalized by considering the industrial density of regions of the different sectors (obtained through the value added). The relative vulnerability index scaled from 0 to 1,0 and 1 being respectively the least vulnerable and most vulnerable state against indirect effects of disasters on the industry).

Vulnerabilities are a starting point to assess the indirect economic losses, particularly the longer term aspects. Here an approach quantifying production losses is combined with input-output approaches (Okuyama, 2007) with recovery functions that have been determined according to a sector's vulnerability. Using a linear input-output model (Leontief, 1986), the potential impacts of Sandy were estimated on different business interruption scenarios of the US economy. As the uncertainties, particularly in the immediate aftermath of the event, are fundamental (i.e., hard to quantify), scenarios were used, which have been proven useful as a means to account for the severe uncertainties (Comes et al., 2011). To construct the scenarios in a systematic way, the indirect costs were split up into several sub-scenarios considering the overall disruption due to the event (across all sectors), the impact of power blackouts and the impact of disruptions of the transportation system. The overall impact depends to a large degree on the assumptions about the disaster recovery. As mentioned in the preceding chapter, assuming that the disruptions of the overall manufacturing sector lasted for two days in the 14 states affected by Sandy, the costs would approximate USD 9.4 billion for the two days of the storm. However, the time needed for the industrial sector to recover must be considered, which extends the time for utilities to recover. The capacity of businesses to restart their activity during this recovery period highly depends on the vulnerability of the sectors. Following this rationale, an ensemble of recovery scenarios (comparable to meteorological ensembles) were calculated by using exponential potential recovery functions with different curvatures (Cimellaro et al., 2010). Depending on the recovery scenario, the indirect costs estimated by the model for 10 days following the storm range from USD 1.4 to 5.6 billion. Assuming that the closure of the stock exchanges and offices affected $30 \%$ of the finance sector US-wide on the two days of the storm, the indirect costs on the economy would approximate USD 9.8 billion. Adding the estimated partial disruption losses during the recovery period to the losses of the two days of total shutdown for all manufacturing sectors, the total business interruption losses are estimated between USD 10.8 and 15.5 billion. Figure 16 illustrates the differences in expected losses for varying industrial sectors (again, differences may arise due to varying vulnerabilities and exposure levels).

\subsection{Observing impacts using social media}

Using data from social media provided by eyewitnesses seems promising; in combination with data from conventional sensors, it provides a more comprehensive picture of the local situation only seconds after an event occurs. This may be an important source of information especially for regions with low infrastructure, where other information of the impact of a catastrophe are scarce. For Hurricane Sandy, we tested the applicability and the potential use of social media.

To get up-to-date information on the characteristics and the impact of the hurricane, data was collected from the tweets of the micro-blogging service Twitter (see Fig. 17). During Hurricane Sandy, 5328029 tweets were collected and stored in near-real time from 29 October to 2 November in our database. These messages were filtered by keywords like hurricane, flood, damage, victims or power outage. About $3 \%$ of the tweets (154890) can be localized by geo-coordinates and be used for further information extraction.

The tweets provide detailed and very local information about Sandy's impact such as "sandy floods \#fdr 63rd street", "Flooding on Pitney Rd is just from a storm drain", or "Some may not have power but we all have phones" (see examples in Table 5). Besides announcements of general damage, the examples give information about flooding (see Sect. 3.3.2) and power outages (Sect. 5.2) at particular locations of the Twitter users. Reports of flooding from eyewitnesses are often the only information source, since data acquisition of flooding in urban areas is difficult as usually no appropriate sensors are installed outside of traditional river channels and water sources.

Furthermore, the spatial and temporal distribution of tweets reporting on power outages may indicate areas and time periods with impaired or unimpaired power supply. 


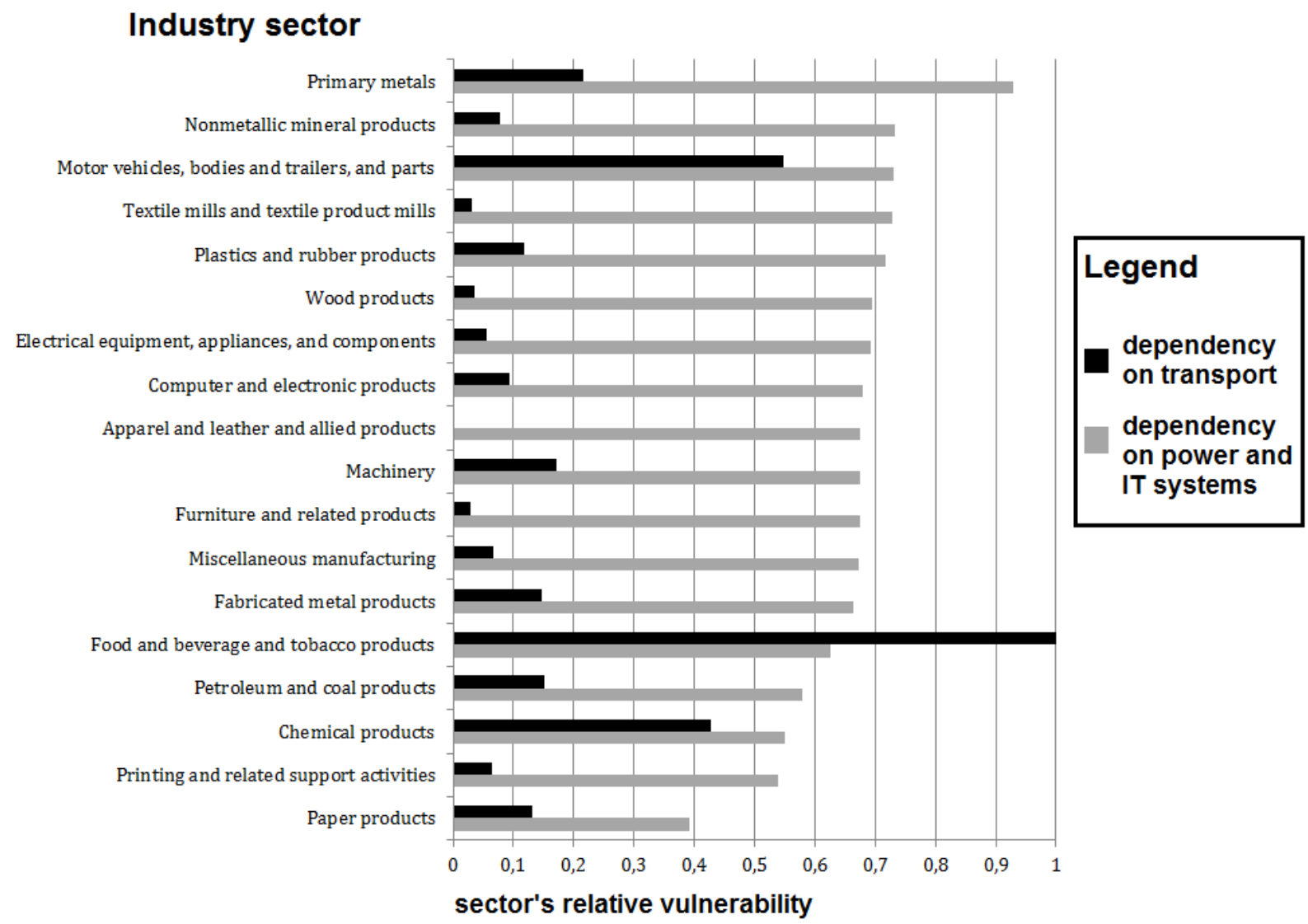

Fig. 15. Transportation and power dependencies of different industrial sectors, taking into account inter-CI dependencies. Black bars indicate transport dependency, grey bars power dependency.

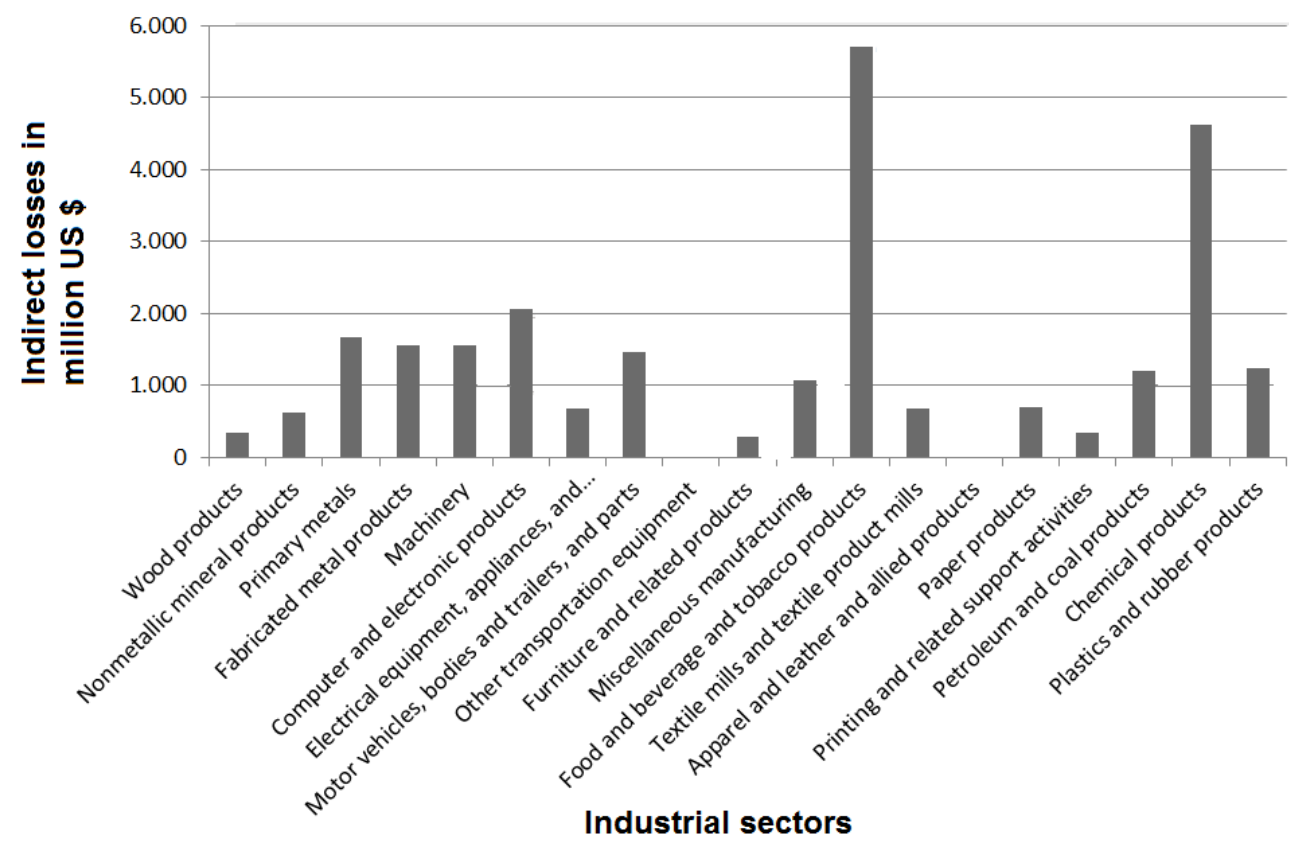

Fig. 16. Assessment of indirect industrial losses due to Sandy. 

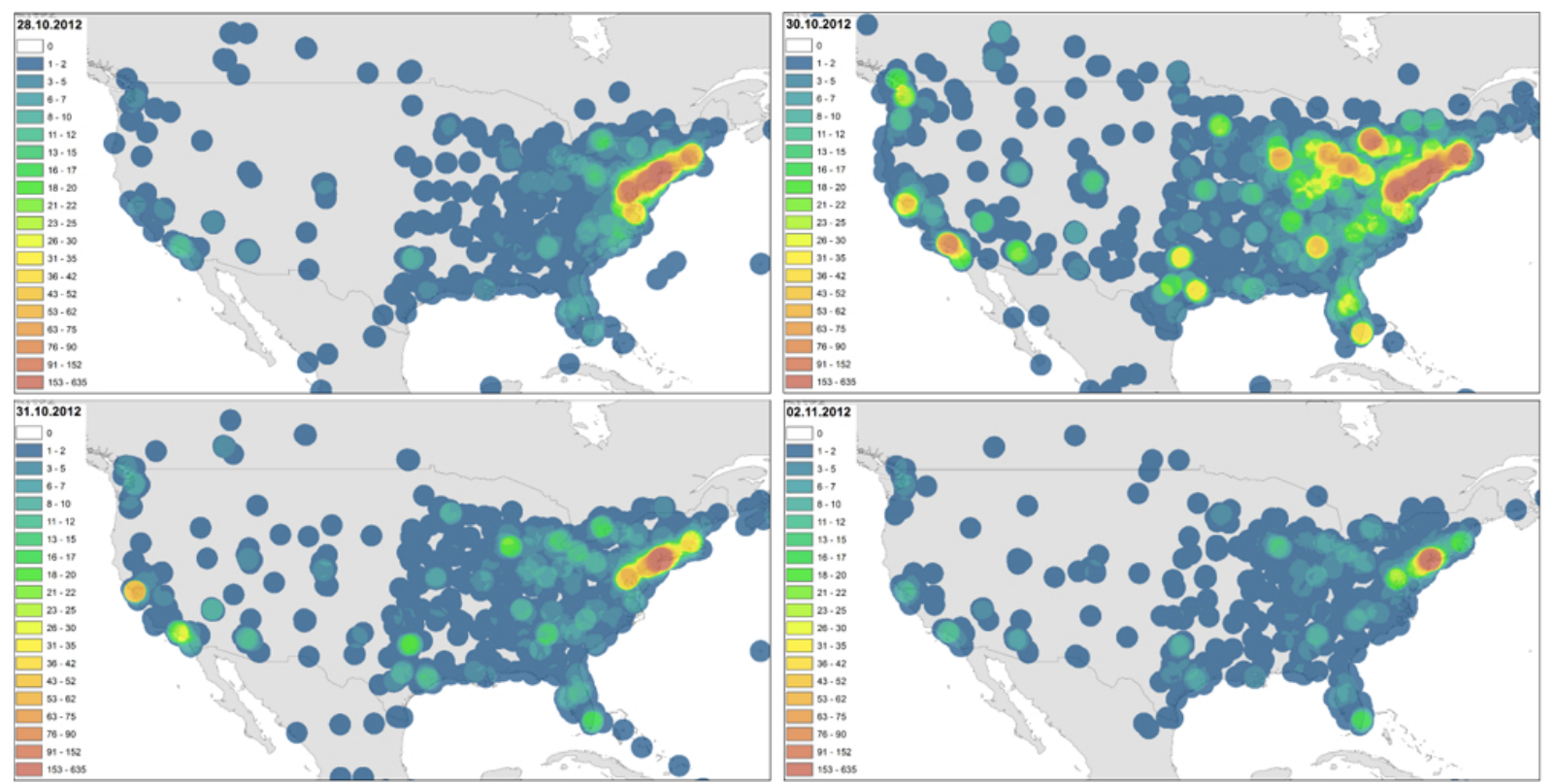

Fig. 17. Density map of the located tweets with the keyword hurricane for a timeline of six days, from 28 October to 2 November 2012 (dates indicated in the figures). The density refers to the number of tweets per $0.05^{\circ}$ grid cell (approximately $5 \times 5 \mathrm{~km}^{2}$ ).

Table 5. Examples of tweets sent during Hurricane Sandy on 30 Oct. 2012; time is in UTC.

\begin{tabular}{llll}
\hline Topic & User & Time & Message \\
\hline Damage & $\begin{array}{l}\text { Lamar Liffridge } \\
\text { Kirk Moore }\end{array}$ & $\begin{array}{l}09: 19: 52 \\
13: 50: 28\end{array}$ & $\begin{array}{l}\text { Wakes up, sees power and can still on, and no damage, yes \#sandy } \\
\text { Severe damage on South Green Street Tuckerton Beach area, boats jumbled } \\
\text { in marinas http://t.co/jhLGBp2m } \\
\text { \#sandy floods \#fdr 63rd street http://t.co/10K0clpi }\end{array}$ \\
& $\begin{array}{l}\text { ELCIRCUITOTV } \\
\text { Bill Speakman }\end{array}$ & $\begin{array}{l}03: 34: 20 \\
09: 26: 27\end{array}$ & $\begin{array}{l}\text { Flooding on Pitney Rd is just from a storm drain. The Conestoga River still } \\
\text { has a couple of feet before reaching the bank. }\end{array}$ \\
& John Powell & $00: 02: 46$ & $\begin{array}{l}\text { I have officially lost power at my home in Glenolden, PA } \\
\text { Pome may not have power but we all have phones \#connected } \\
\text { infrastructure }\end{array}$ \\
& $\begin{array}{l}\text { Preston Kilgore } \\
\text { Lis Kalogris }\end{array}$ & $\begin{array}{l}06: 20: 27 \\
13: 02: 38\end{array}$ & $\begin{array}{l}\text { Here in the EOB Garden we have lost power but so far no visible major } \\
\text { damage. Worried about our many tulip poplars. All of you, be safe. XO }\end{array}$ \\
& &
\end{tabular}

Absence of any tweets or a significant decrease of tweets, respectively, may indicate presumably breakdown or impairment of supply networks. Additionally, the spatial and temporal distribution of tweets allow for inferring intensity and impact of the event in a larger area. An example of the large potential of tweets for spatio-temporal investigations of technical or natural hazards is given by Fig. 17 that shows all geolocated tweets during Hurricane Sandy with the keyword hurricane. The time series in Fig. 4 show that the number of tweets corresponds well with maximum wind speeds and storm surges.

\section{Conclusions}

In this paper, we presented a multidisciplinary analysis of the causes, hazardous effects, and consequences associated with Hurricane Sandy. This examination was done in an interdisciplinary approach by collecting and compiling scattered and distributed information from available databases and sources via the Internet, by application of own methodologies and simple input-output models, and by expert knowledge.

Hurricane Sandy was an extraordinary event for the US in particular due the simultaneous occurrence of specific meteorological features leading to an unusual storm's track, the multihazard nature that further amplified intensities, and the cascades of adverse events in the aftermath that aggravated the direct impacts significantly. The track more or less from the south to the north was mainly the result of a blocking by an extended high pressure system. Thus, Sandy hit 
a region in the US that has rarely been affected by hurricanes in the past but is densely populated and very vulnerable to such an unexpected event. Since recording, Sandy was only the third hurricane to have made landfall in New Jersey. Most unusual was the very large spatial extent of up to $1700 \mathrm{~km}$, primarily a result of the interaction of the hurricane with an upper-tropospheric trough. This interaction led to a rapid extra-tropical transition shortly before landfall and further increased the strength of the storm in terms of wind speed and precipitation. Significant storm surges due to high wind speeds towards the eastern US coast occurred simultaneously with high astronomical tides. This caused total record-breaking storm surges along the US Mid-Atlantic and New England coastlines.

Along the track from the Caribbean up to the eastern US, one of the poorest (Haiti) and one of the richest countries (US) were devastated with different - though characteristic patterns of impact and loss. Apart from fatalities (about 80 in Haiti and Cuba; 142 in the US) and direct economic losses (about USD 4.2 billion in the Caribbean; 78 to 97 billion in the US), the rich and poor were struck by cascades of adverse events that aggravated the direct impacts significantly.

Haiti, only slowly recovering from the 12 January 2010 earthquake that destroyed $121 \%$ of Haiti's (nominal) GDP and killed more than 100000 people, lost another $4.5 \%$ GDP. Crop destruction triggered danger of malnutrition for 450000 to 1500000 people. Many of the 350000 people still living in temporary shelters and camps suffered from destruction of those shelters. In addition, many cholera treatment centers, other medical facilities and schools were destroyed or hampered in functioning. An increase in cholera infected persons is observed although current numbers seem to indicate that no major cholera outbreak increase will follow.

The US suffered from the high direct losses to residential and industrial buildings but also from power outages ranging between several days and two weeks for individual households, subsequent supply problems with gas, and business interruption (particularly in transport-dependent industry sectors). Cold weather imposing harsh conditions on people who depend on electric heating and the uncontrolled electric fires fed by heavy storms were additional aggravating factors. The role of the proximity of Sandy to the US presidential elections remains a speculative issue until researched in detail.

The key scientific question addressed in this paper is to what extent, with which databases and which models can the losses and impacts of a catastrophic event like Sandy be extracted and predicted several hours after the event. Our working hypothesis is that the potential for near-real-time analysis has changed significantly with the Internet and the social media that generate huge amounts of information from the very onset of a disaster. Utilizing these resources in combination with analytic tools developed by CEDIM and historic loss and event databases provides a framework for near-real-time analysis and predictions.
Whereas the first CEDIM report was published only several hours after Sandy made landfall on the US east coast, the second report with a focus on damage estimates for the affected states of Pennsylvania, New Jersey and New York and comparisons to past events was published by 7 November 2012. Risk modelers such as EQECAT and other published earlier estimates, but they underestimated the losses by a factor of 2 to 3 . There is obviously a trade off between the value of loss information and uncertainty, which is hard to quantify. Early information is in high demand but also highly uncertain. The determination of the trade-off points is obviously user-dependent and quantification of uncertainties in near-real-time loss estimation a high-profile topic. Overall, our work on Sandy shows that the forensic disaster analysis is possible and useful directly after the event occurred. With our new approach of FDA we fill the gap between the first and rough damage estimations and events descriptions performed by insurance companies and the FORIN concept of IRDR.

Tracking power outages and estimating downtimes requires a combination of simple models and crowd-sourcing tools, which should be brought closer together than was managed during Sandy. The distribution of losses to different sectors of the economy is done with a simple input-output model and, given the data sparseness at an early stage of the analysis, is a valid methodology. In this manner, fast assessment of indirect losses due to business disruptions could be achieved. First estimates were already released prior to Sandy's landfall. Due to the ease of adaptation of all models, the analyses were refined in the aftermath of the event as more information was published (e.g., about the most severely affected areas and the extent and duration of power blackouts). An equally simple model allows defining an industrial vulnerability parameter for states (and potentially other administrative units) that immediately indicates where aggravating impacts are to be expected even if the state is less affected in terms of hazard and current loss numbers. The estimates provided here do, however, not consider all indirect costs: beyond output losses all indirect losses across globalized supply networks should be considered. Additionally, the dynamic evolution of the losses (including, e.g., price effects) will be subject of our future investigations.

Although our working hypothesis was essentially confirmed, it has been learnt that linking methods and models has more potential than are currently exploited, and in addition, that more systematic utilization of historic databases might hold the key for uncertainty estimation in direct and indirect loss predictions.

Acknowledgements. The Center for Disaster Management and Risk Reduction Technology (CEDIM) is an interdisciplinary research center in the field of disaster management funded by Helmholtz Centre Potsdam - German Research Centre for Geoscience (GFZ), and Karlsruhe Institute of Technology (KIT). We acknowledge support by Deutsche Forschungsgemeinschaft and Open Access 
Publishing Fund of KIT. The authors thank the helpful comments of the anonymous reviewers.

The service charges for this open access publication have been covered by a Research Centre of the Helmholtz Association.

Edited by: A. Mugnai

Reviewed by: three anonymous referees

\section{References}

Alward, G., Siverts, E., Taylor, C., and Winter, S.: Micro IMPLAN, User's Guide, Version 91-F., Tech. rep., USDA Forest Service, Land Management Planning Systems Group, 1992.

Apel, H., Thieken, A. H., Merz, B., and Blöschl, G.: A probabilistic modelling system for assessing flood risks, Nat. Hazards, 38, 79100, 2006.

Bayleyegn, T., Wolkin, A., Oberst, K., Young, S., Sanchez, C., Phelps, A., Schulte, J., Rubin, C., and Batts, D.: Rapid assessment of the needs and health status in Santa Rosa and Escambia Counties, Florida, after Hurricane Ivan, September, 2004, Disaster Manage. Response, 4, 12-18, 2006.

Burton, I.: Forensic disaster investigations in depth: A new case study model, Environment, 52, 36-41, 2011.

CDEMA: Summary of impact of Hurricane Sandy on CDEMA participating states, available at: http://reliefweb.int/sites/reliefweb. int/files/resources/Full_Report_4418.pdf (last access: 10 October 2013), 2012.

Chang, S. E., McDaniels, T. L., Mikawoz, J., and Peterson, K.: Infrastructure failure interdependencies in extreme events: power outage consequences in the 1998 Ice Storm, Nat. Hazards, 41, 337-358, 2007.

Cimellaro, G. P., Reinhorn, A. M., and Bruneau, M.: Framework for analytical quantification of disaster resilience, Eng. Struct., 32, 3639-3649, 2010.

Comes, T. and Schultmann, F.: Enhancing Robustness Against Natural Hazards in Supply Chain Management, 10th International Conference on Applied Mathematical Optimization and Modelling, 2012.

Comes, T., Hiete, M., Wijngaards, N., and Schultmann, F.: Decision Maps: A Framework for Multi-Criteria Decision Support Under Severe Uncertainty, Decis. Support Syst., 52, 107-118, 2011.

Cuomo, A.: Governor Cuomo holds meeting with New York's congressional delegation, Mayor Bloomberg and regional county executives to review damage assessment for the State in the wake of Hurricane Sandy, available at: http://www.governor.ny. gov/press/11262012-damageassessment (last access: 10 October 2013), 2012.

Cutter, S. L., Boruff, B. J., and Shirley, W. L.: Social vulnerability to environmental hazards, Soc. Sci. Q., 84, 242-261, 2003.

Daniell, J. E.: CATDAT Natural Disasters Socioeconomic Loss Database - 2012 Report, Tech. rep., General Sir John Monash Foundation, KIT, Karlsruhe, Germany, 2012.

Daniell, J. E., Khazai, B., Wenzel, F., and Vervaeck, A.: The CATDAT damaging earthquakes database, Nat. Hazards Earth Syst. Sci., 11, 2235-2251, doi:10.5194/nhess-11-2235-2011, 2011.
Daniels, R. J., Kettl, D. F., and Kunreuther, H.: On risk and disaster: Lessons from Hurricane Katrina, University of Pennsylvania Press, 2006.

DeStefano, M.: Bloomberg: Sandy Losses Total $\$ 19$ billion, available at: http://www.newsday.com/ bloomberg-sandy-losses-total-19-billion-1.4262746 (last access: 10 October 2013), 2012.

DOE: Hurricane Sandy Situation Reports 1-20, available at: http://www.oe.netl.doe.gov/named_event.aspx?ID=67 (last access: 10 October 2013), 2012a.

DOE: Hurricane Sandy Nor'easter Situation Report 1-11, available at: http://www.oe.netl.doe.gov/named_event.aspx?ID=68 (last access: 10 October 2013), 2012 b.

ECHO: Impact of SANDY in the Caribbean - ECHO sitrep 3, 06 Nov 2012, available at: http://ec.europa.eu/echo/images/map/ caribbean_sandy.pdf (last access: 10 October 2013), 2012.

Fahey, J.: Power outages after Hurricane Sandy weren't unusually long after all, The Associated Press, 2012.

IFRC: Emergency appeal No MDRCU002, Glide No: TC-2012000180CUB 5 November 2012, available at: http://reliefweb.int/ sites/reliefweb.int/files/resources/MDRCU002EA.pdf (last access: 10 October 2013), 2012a.

IFRC: Cuba - Hurricane Sandy: The world's newest silent disaster?, available at: https://www.ifrc. org/fr/nouvelles/communiques-de-presse/general/

hurricane-sandy-the-worlds-newest-silent-disaster/ (last access: 10 October 2013), 2012b.

IRDR: Forensic Investigations of Disasters: The FORIN project, (IRDR FORIN Publication No. 1), Tech. rep., Beijing, Integrated Research on Disaster Risk, 2011.

Jones, S., Harr, P., Abraham, J., Bosart, L., Bowyer, P., Evans, J., Hanley, D., Hanstrum, B., Hart, R., Lalaurette, F., Sinclair, M. R., Smith, R. K., Thorncroft, C.: The extratropical transition of tropical cyclones: Forecast challenges, current understanding, and future directions, Weather Forecast., 18, 1052-1092, 2003.

Kleindorfer, P. R. and Saad, G. H.: Managing Disruption Risks in supply Chains, Production Operations Manage., 14, 53-68, 2005.

Leontief, W.: Input-Output Economics, Oxford University Press, 1986.

Merz, M.: Entwicklung einer indikatorbasierten Methodik zur Vulnerabilitätsanalyse für die Bewertung von Risiken in der industriellen Produktion, KIT-Verlag, 2011.

Messner, F., Penning-Rowsell, E., Green, C. H., Meyer, V., Tunstall, S., and van der Veen, A.: Evaluating flood damages: guidance and recommendations on principles and methods, Integrated Flood Risk Analysis and Management Methodologies, FLOODsite Report, 2007.

Mühr, B., Kunz, M., Kunz-Plapp, T., Daniell, J. E., Khazai, B., Vannieuwenhuyse, M., Comes, T., Elmer, F., Schröter, K., Leyser, A., Lucas, C., Fohringer, J., Münzberg, T., Trieselmann, W., and Zschau, J.: CEDIM FDA-Report on Hurricane Sandy 2230 October 2012, 2nd Report: Information as of 08 November 2012, 18 UTC, available at: https://www.cedim.de/download/ CEDIMFDAreportSandy_2012_no2.pdf (last access: 10 October 2013), 2012.

OCHA: The Caribbean: Hurricane Sandy Situation Report No. 2 (as of 19 November 2012), available at: http://reliefweb.int/ 
sites/reliefweb.int/files/resources/Situation_Report_351.pdf (last access: 10 October 2013), 2012a.

OCHA: Overview Map 31 Oct 2012: Impact of Tropical Storm Sandy, available at: http://reliefweb.int/sites/reliefweb.int/files/ resources/Sandymap.pdf (last access: 10 October 2013), 2012b.

OCHA: UN Relief Agency Estimates 1.8 Million Have Been Affected by Hurricane Sandy, available at: http://reliefweb.int/report/haiti/un-relief-agency-estimates (last access: 10 October 2013) 2012c.

OCHA: Haiti: Hurricane Sandy Situation Report No. 04 (as of 9/11/2012), available at: http://reliefweb.int/report/haiti/ haiti-hurricane-sandy-situation-report-no-04-09112012 (last access: 10 October 2013), 2012d.

Okuyama, Y.: Economic Modeling for Disaster Impact Analysis: Past, Present and Future, Economic Syst. Res., 19, 115-124, 2007.

Penning-Rowsell, E., Johnson, C., Tunstall, S., Tapsell, S., Morris, J., Chatterton, J., Coker, A., and Green, C.: The Benefits of flood and coastal defence: techniques and data for 2003, Flood Hazard Research Center, Middlesex University, Middlesex University Press, 2003.

Platz, E., Cooper, H. P., Silvestri, S., and Siebert, C. F.: The impact of a Series of Hurricanes on the Visits to Two Central Florida Emergency Departments, J. Emerg. Med., 33, 39-46, 2007.

Rinaldi, S. M., Peerenboom, J. P., and Kelly, T. K.: Identifying, understanding, and analysing critical infrastructure interdependencies, Control Systems, IEEE, 21, 11-25, 2001.

Rose, A., Benavides, J., Chang, S. E., Szczesniak, P., and Lim, D.: The Regional Economic Impact of an Earthquake: Direct and Indirect Effects of Electricity Lifeline Disruptions, J. Reg. Sci., 37, 437-458, 1997.

Swiss Re: Sigma Report No 2/2006: Natural catastrophes and manmade disasters in 2006, Tech. rep., Swiss Reinsurance Company, 2006.
Tierney, K. J.: Business Vulnerability and Disruption: Data from the 1993 Midwest Floods (Draft), Paper presented at the 41st North American Meetings of the Regional Science Association International, Niagara Falls, Ontario, available at: http://dspace.udel. edu:8080/dspace/bitstream/19716/596/1/PP213.pdf (last access: 10 October 2013), 1994.

Trapasso, C.: Families return to Breezy Point after devastating fire during Hurricane Sandy destroys 111 houses, NY Daily News article, 1st November 2012, available at: http://www.nydailynews.com/new-york/queens/ (last access: 10 October 2013), 2012.

USGS: Water-resources data for the United States, Water Year 2011: U.S. Geological Survey Water-Data Report WDRUS-2011, available at: http://wdr.water.usgs.gov/wy2011/pdfs/ 01638500.2011.pdf (last access: 1 March 2013), 2012.

Webb, G. R., Tierney, K. J., and Dalhamer, J. M.: Predicting longterm business recoverey from disaster: a comparison of the Loma Prieta earthquake and Hurricane Andrew, Environ. Hazards, 4, 45-58, 2002.

Wenzel, F., Daniell, J. E., Khazai, B., Mühr, B., Kunz-Plapp, T., Markus, M., and Vervaeck, A.: Real-time forensic disaster analysis, Geophys. Res. Abstr., Vol. 14, EGU2012-1328, EGU General Assembly 2012, 22-27 April, Vienna, Austria, 2012.

Wood, E. F. and Rodriguez-Iturbe, I.: A Baysian approach to analyzing uncertainty among flood frequency models, Water Resour. Res., 11, 839-843, 1975.

Zimmerman, R. and Restrepo, C. E.: The next step: quantifying infrastructure interdependencies to improve security, Int. J Crit. Infrastruct., 2, 215-230, 2006.

Zimmermann, R., Lave, L., Restrepo, C., Dooskin, N., Hartwell, R., Miller, J., Remington, W., Simonoff, J., and Schuler, R.: Electricity Case: Economic Cost Estimation Factors for Economic Assessment of Terrorist Attacks, New York University, Wagner Graduate School, Institute of Civil Infrastructure Systems, 2005. 